\author{
ARTIFICIAL SATELLITES, Vol. 54, No. 4 - 2019 \\ DOI: 10.2478/arsa-2019-0011
}

sciendo

\title{
THEORETICAL PROBLEMS UNDERLYING SPRITE OBSERVATIONS OF THE PLANNED TARANIS SATELLITE MISSION
}

\author{
Paweł Jujeczko \\ Space Research Centre of the Polish Academy of Sciences, \\ Bartycka 18A, 00-716, Warszawa, Poland \\ e-mail: pjujeczko@cbk.waw.pl
}

\begin{abstract}
Tool for the Analysis of Radiations from lightnings and Sprites (TARANIS) is a French Space Agency's (CNES) satellite mission planned for launch in 2020. It is designed for investigating phenomena related to thunderstorm activity, transient luminous events (TLEs) and amongst them - red sprites. The satellite is equipped with cameras, photometers, energetic particles detectors, ion probe and electromagnetic sensors of wide frequency spectrum. It will be the most versatile satellite for measuring TLEs ever sent to space. In this article, theories that are fundamental for understanding sprites and sprites-related measurements of TARANIS mission are presented. The current state of sprites phenomenology and their possible generation mechanisms are presented. The article briefly covers streamer discharges, cloud charge structure at the TLE occurrence, electric breakdown of the air and Runaway Relativistic Electron Avalanche (RREA). At the end, TARANIS mission equipment and goals that are related to presented theories are presented.
\end{abstract}

Keywords: Transient Luminous Event (TLE), TARANIS, sprite, lightning

\section{INTRODUCTION}

Upper atmosphere discharges were theoretically predicted by Wilson in 1920s (Wilson, 1924, 1925); however, it was not until 1990 that the first occurrence of a transient luminous event (TLE) has been reported (Franz et al., 1990). TLEs are phenomena that occur above thunderstorms; they last for very short time (are transient) but can be optically registered. They occur in stratosphere, mesosphere, and lower ionosphere, depending on the type of the TLE. Since their discovery, the set of TLEs has grown large, and now it includes sprites, halos, elves, blue starters, blue jets, gigantic jets, and others (see, e.g., Cooray, 2014; Rakov and Uman, 2003; Surkov and Hayakawa, 2012).

Studying sprites and jets can serve for better understanding of sparks and lightnings because of similar mechanisms that probably drive them (Surkov and Hayakawa, 2012). However, conditions in stratosphere and mesosphere, such as low pressure, lead to larger spatial scales. Thanks to the similarity relations, TLEs can be compared with laboratory measurements of sparks (Ebert et al., 2010) and cloud to ground discharges. There is still much work to do in this field, because the theory of atmospheric discharges is still far from accurate. For example, the initiation process of a lightning remains a big question (Iudin et al., 2018) just as processes of streamers propagation (Dwyer and Uman, 2014). 
The influence of sprites in the global electric circuit was examined by, for example, Rycroft and Odzimek (2010).

In this article, the actual state of knowledge standing behind sprites with a stress put on potential outcomes of the planned Tool for the Analysis of RAdiations from lightNIng and Sprites (TARANIS) mission that may serve for proving hypotheses, developing existing theories and investigating new phenomena is presented.

\section{BRIEF HISTORY OF SPRITES OBSERVATIONS}

Ground and aircraft observations include radio and optical measurements. First TLE, a sprite, was recorded by an accident using low-light-level camera and was described by Franz et al. (1990). For the past 30 years, numerous campaigns have been run on the ground to investigate TLEs (e.g., Cummer, 2003; Cummer et al., 2006; Gerken and Inan, 2003; Gerken et al., 2000; Kulak et al., 2014; Neubert et al., 2001; Sentman et al., 1995; Wescott et al., 1995, 2001; Winckler et al., 1996). Despite this big effort, many of physical mechanisms related to sprites remain unknown, for example, beads (Luque and Gordillo-Vázquez, 2011) and subtle (microscale) structure (Błęcki and Mizerski, 2018) in sprites.

TLEs have also been observed from the orbit, for example, by space shuttle Columbia during its 2003 mission STS-107 in Mediterranean Israeli Dust Experiment (MEIDEX) sprite campaign (Yair, 2004). Formosat's-2 instrument Imager for Sprites and Upper Atmospheric Lightning (ISUAL) observed more than 31,000 TLEs during the first 10 years of work, and it was the first satellite that was designed for imaging the upper atmospheric events (Chern et al., 2014). Later on, the Lightning and Sprite Observations (LSO) device was mounted on the International Space Station (ISS). It allowed for developing a method of observing sprites from nadir. This method was designed by a team involved in preparing the DEMETER mission and upcoming TARANIS (Blanc et al., 2004). Other TLE-related instruments on board the ISS were Global Lightning and Sprite Measurement (GLIMS) (Sato et al., 2015) and recently Atmosphere-Space Interactions Monitor (ASIM) that is closely connected to TARANIS mission (Neubert et al., 2019). There were also experiments conducted by astronauts on the ISS that covered shorter durations (Blanc et al., 2004; Chanrion et al., 2017; Jehl et al., 2013). Also other missions that cover electromagnetic and optical measurements aimed towards the Earth can be useful for the examination of TLEs, for example, missions designed for measuring the magnetic field of the Earth, such as SWARM (Friis-Christensen et al., 2006).

New Russian micro-satellite of Chibis family, Chibis-AI, for measuring atmospheric and ionospheric phenomena is also planned for 2020. It will be a continuation of Chibis-M designed for measuring electromagnetic radiation over thunderstorms (Zelenyi et al., 2014).

\section{PHENOMENOLOGY OF SPRITES}

Typical sprite is schematically pictured on Figure 1. Its upper part belongs to the so-called diffuse region where Townsend electron multiplication is developing and where no distinct structures are shown; lower part shows structures resembling tendrils. This filamentary propagation region is characterized by strong attachment of ambient electrons and single electrons developing into streamers (Pasko, 2006). It is now accepted that sprite's discharges lower part are of streamer type, what is based on aforementioned filamentary structure shown by telescopic imaging (Gerken and Inan, 2003; Gerken et al., 2000; Marshall and Inan, 2005).

Early high-speed video imaging of sprites showed downward moving positive streamers, but, later on, it was shown that from the structures preconditioned by downward-directed streamers, there also develop upward-propagating negative streamers (Stenbaek-Nielsen et al., 2013). The high-speed videos helped to classify sprites as columnar or C-sprites (those that 
have only downward-propagating streamers visible) and carrot sprites with many upwardpropagating streamers too (Stenbaek-Nielsen and McHarg, 2008). Sometimes there are only few upward-propagating streamers and sprite seems to be a combination of two aforementioned types (Stenbaek-Nielsen et al., 2013).

Sprites appear in the mesosphere at $40-80 \mathrm{~km}$ above the ground level and last from few to $\sim 200 \mathrm{~ms}$ (Sentman et al., 1995). Often in the diffuse region before the appearance of a sprite, a wide glow called "sprite halo" occurs. It lasts for 2-10 ms and extends vertically to $60-90 \mathrm{~km}$ at an altitude of $75-85 \mathrm{~km}$. Sometimes it is followed by one or more sprites but not always (Barrington-Leigh et al., 2001; Wescott et al., 2001). Halo can extend horizontally from 40 to 70 km (Pasko, 2007).

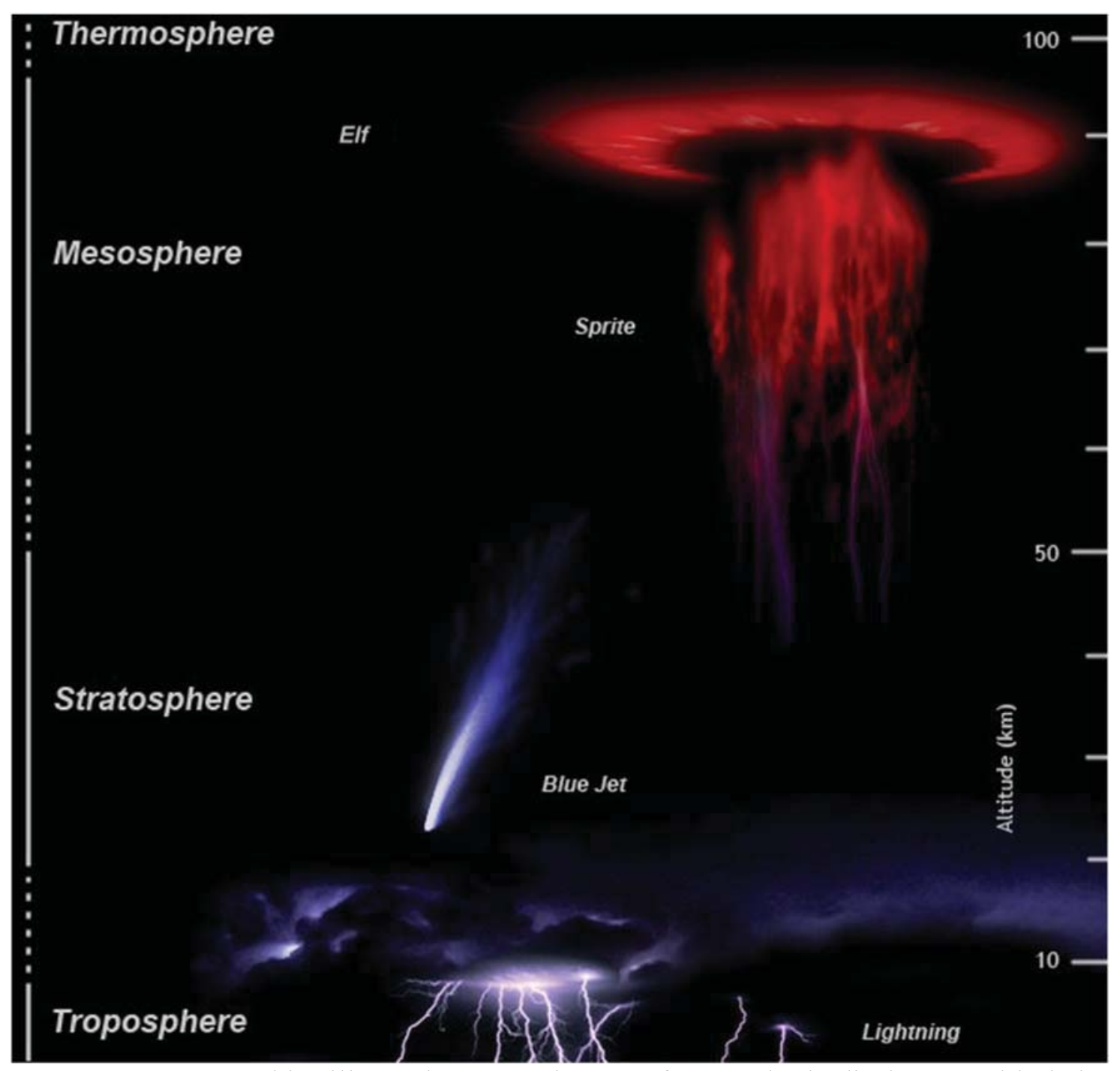

Fig. 1. Graphics illustrating several types of atmospheric discharges with their example altitude and scale (Abestrobi, 2008)

Single columnar sprites have $\sim 10 \mathrm{~km}$ extent vertically and less than $1 \mathrm{~km}$ horizontally. However, sprites often appear in clusters that can extend laterally more than $\sim 40 \mathrm{~km}$. (Rakov and Uman, 2003, p. 487)

Sprites are usually preceded by positive lightnings (+CGs) (Pasko et al., 2012); however, rare cases of sprites triggered by negative cloud to ground discharges (-CGs) are known (e.g. Barrington-Leigh et al., 1999). Why some lightnings are called "positive" will be described in Section 5. 
Most of the sprites occur in a radius of $50 \mathrm{~km}$ around the triggering lightning and after less than $20 \mathrm{~ms}$ from the trigger (São Sabbas et al., 2003). Sprites of longer delay are considered long-delayed sprites and were seen to exhibit properties different from those that appear faster (Li et al., 2008).

Important factor in sprites imaging is their visible spectrum. Sprites strongest emission band is $762.7 \mathrm{~nm}$, first positive band of $\mathrm{N}_{2}\left(\mathrm{~N}_{2} 1 \mathrm{P}\right)$. As it lays in strong $\mathrm{O}_{2}$ absorption band near 761.9 $\mathrm{nm}$, it is not visible in ground measurements, thanks to the fact that above the sprite, there is less oxygen than below; however, it is visible from space. What is more, at the same time, the emission from lightnings at this wavelength is damped by the air above them (Blanc et al., 2006).

Other useful bands in TLE measurement is the ultraviolet band of $337 \mathrm{~nm}$, related to $\mathrm{N}_{2} 2 \mathrm{P}$ and the 600- to 900-nm range (Blanc et al., 2006; Boccippio et al., 2002). One of the strongest emission bands of lightnings is $777 \mathrm{~nm}$, which is related to the atomic oxygen excitation (Christian et al., 1989). Lightnings are important as their activity amplifies the electric field in the mesosphere, allowing for the occurrence of TLEs. The 127-240 nm (ultraviolet to farultraviolet) Lyman-Birge-Hopfield (LBH) band of nitrogen was shown by Formosat's-2 ISUAL to be emitted by lightnings and strongly absorbed by the air (Mende et al., 2006). Thus its relation to less-damped 777-nm wave strength can tell the altitude of the cloud to ground discharge by knowing the damping coefficients for these two wavelengths (Chanrion et al., 2019).

\section{ELECTROMAGNETIC PROPERTIES OF SPRITES AND THEIR TRIGGERING LIGHTNINGS}

Generally, positive cloud to ground discharges (+CGs) are less common than -CGs. They account for around $10 \%$ of all the cloud to ground lightnings, and the latter ones are the rest (Nag and Rakov, 2012). Both these types of discharges strongly radiate in the extremely low frequency (ELF) range $(0.3-3 \mathrm{kHz})$. The ELF measurements give opportunity to distinguish positive lightnings from negative ones (Boccippio et al., 1995).

ELF and very low frequency (VLF; $3-30 \mathrm{kHz}$ ) waves can propagate inside Earthionosphere cavity for long distances because of low attenuation in this frequency range (Taylor and Sao, 1970). Most of these waves stay inside the Earth-ionosphere waveguide and are referred as "sferics," but some part of the energy can escape up to the magnetosphere, becoming a $0^{+}$whistler (Lefeuvre et al., 2009). Whistlers are waves travelling along magnetic field lines and trapped between magnetic mirrors created by that field. The number standing by a whistler wave's name (e.g., " 0 " and " 1 ") is the count of the reflections between the magnetic mirrors. The sign ("+" or "-") refers to wave propagating along the magnetic field line and upward from the Earth toward the equator plane (plus) or downward toward the ground when it already passed the equator (minus).

First recording of satellite ELF and VLF signatures related to sprite-producing lightnings was reported by Lefeuvre et al. in 2005 (Lefeuvre et al., 2009). Those measurements showed that electron and proton $0^{+}$whistlers from thunderstorms exhibiting sprite activity can be observed; however, potential signatures of sprite currents may be overwhelmed by proton whistlers.

Cummer et al. (1998) were measuring ELF/VLF radiation from the ground during sprite production. They measured only ELF but no VLF radiation during sprite initiation and showed that it is related to currents flowing in sprites body. On the other hand, Ohkubo et al. (2005) were the first to show ELF and VLF signatures preceding and lasting during sprite activity, stating that it would suggest intracloud discharges (ICs). They argued with aforementioned 
outcome of Cummer et al. stating that finding no VLF in their signal was related to the fact that their receiver was too far from the event $(\sim 2,000 \mathrm{~km})$. As VLF signals are strongly attenuated according to the distance (Johnson and Inan, 2000), shorter distance of Japanese observations $(250-600 \mathrm{~km})$ allowed the observation of signal related to the IC discharges. However, later on Cummer et al. (2006) showed no lightning activity seen from satellite observations at the time when sprite occurred and ELF signal was present. This gives strong evidence that the ELF signal indeed was related to sprite current. Also other later works used ELF signal to estimate sprite current (Lu et al., 2013; Mlynarczyk et al., 2015).

Researches show that ICs may play an important role in the generation of sprites of carrot type (Neubert et al., 2008; van der Velde et al., 2006). ICs are hard to measure by low-frequency ground systems but can be measured by very high frequency (VHF; 30-300 MHz) systems such as SAFIR, although only in short range from the discharge (Drüe et al., 2007) and by spacebore observations (see, e.g., FORTE mission results [Jacobson et al., 2011; Jacobson and Light, 2003]). The satellite-bore observation can give the information on altitude of the IC, thanks to transionospheric pulse pairs (TIPPs) - pairs of radio frequency signals coming from the source inside a cloud from two different ways. One way is a direct path from the source to the receiver onboard satellite; the other is a path through a reflection from the ground. For example, if the echoed signal is delayed by $50 \mu$ s and the measurement was made in zenith (directly above the IC), then the echo propagation is $50 \mu \mathrm{s} \times \mathrm{c}=15 \mathrm{~km}$ and the IC height is $\sim 7.5 \mathrm{~km}$ because of doubled propagation path between the discharge source and the ground (Jacobson and Light, 2003).

Błęcki et al. (2009) showed that the VLF signal associated with sprite-producing lightnings in satellite-bore measurements decreases over longer time than the one of a non-spriteproducing discharge. This could imply sprite current or IC activity. Both of these details would be interesting from the point of view of examining sprites. Other satellite-bore measurements at ELF/VLF showed a possibility of remote sensing of sprite-triggering discharges from space (Lefeuvre et al., 2009).

Parrot et al. (2013) used satellite VLF data to provide proofs for the formation of ionization columns above the thunderstorms, especially in the places where sprite-producing +CGs occur. This is legitimate as those strong lightnings exceed the level of the ordinary lightning current. Particles precipitated in these lightnings can cause extra ionization by the mechanism described in Section 7 and 8.

\section{CLOUD CONDITIONS BEFORE THE GENERATION OF A SPRITE}

Basically, a thundercloud has most of its positive charge laying above its main negative charge. This is called the main dipole of the cloud (Stolzenburg and Marshall, 2008), shown in Figure 2. Nevertheless, this simple approach does not explain all the details of thundercloud's charge structure. For example, Stolzenburg et al. (1998) examined 20 different storms and found out that basic structure along the convective updraft (the core region of a cloud) consists of four charged regions with main dipole placed in the middle of the cloud but additional weak positive charge was at the bottom of the cloud and usually weak and shallow negative charge was at the very top (screening layer). In many models, the tripolar structure is used. It is similar to the one described by Stolzenburg et al., whereas it is neglecting the uppermost negative screening layer (Rakov, 2013, p. 69).

The electrification of the thundercloud comes from small-scale processes of electrification of single cloud's particles known as hydrometeors that are later moved to separate regions in the cloud. The dominant process for hydrometeors electrification is the graupel-ice mechanism, where collisions between ice crystals and large graupel particles lead to electrification in the 
presence of supercooled water droplets (droplets that remain in liquid state despite that the temperature is below $0^{\circ} \mathrm{C}$ ). More information on clouds electrification can be found in Rakov (2013, p. 84).

As it was already mentioned, most of the sprites are caused by positive cloud to ground lightnings (+CGs). These lightnings are often present in massive thunderclouds systems with many charge layers such as mesoscale convective systems (MCSs) (Lang et al., 2004). During the time before the lightning stroke (left side of Figure 2), positive charge at high parts of the cloud is shielded from the ionosphere by moving negative space charge in conductive air above the cloud (shielding layer). A small part of electric field $\mathrm{E}$ is directed upward and leads to flow of current from higher potential of the cloud (that can be of the order of $100 \mathrm{MV}$ [Marshall and Stolzenburg, 2001]) to the ionosphere of potential $\sim 250 \mathrm{kV}$ (where potential is measured in relation to the ground; Aplin et al., 2008). When strong +CG lowers great amount of positive charge to the ground, the effect is that the negative charge becomes the dominating one in the thundercloud, what brings the reversal of electric field $\mathrm{E}$ between the cloud and the ionosphere (right side of Figure 2). The created field is much higher than before as the shielding mechanism does not work for the duration of relaxation time $\tau(h)=\frac{\varepsilon_{0}}{\sigma_{a}(h)}$ (where $\varepsilon_{0}$ is the permittivity of free space and $\sigma_{\mathrm{a}}$ is the air conductivity). This quasi-stationary field gives the possibility to the formation of sprites because of the acceleration of the electrons and related ionization (Pasko, 2006). For altitudes related to sprite discharges $(60-80 \mathrm{~km}) \tau \sim 1-15 \mathrm{~ms}$ following the intense lightnings, which is in accordance with the observed emissions (Pasko et al., 1997).

Ionosphere: $+250 \mathrm{kV}$

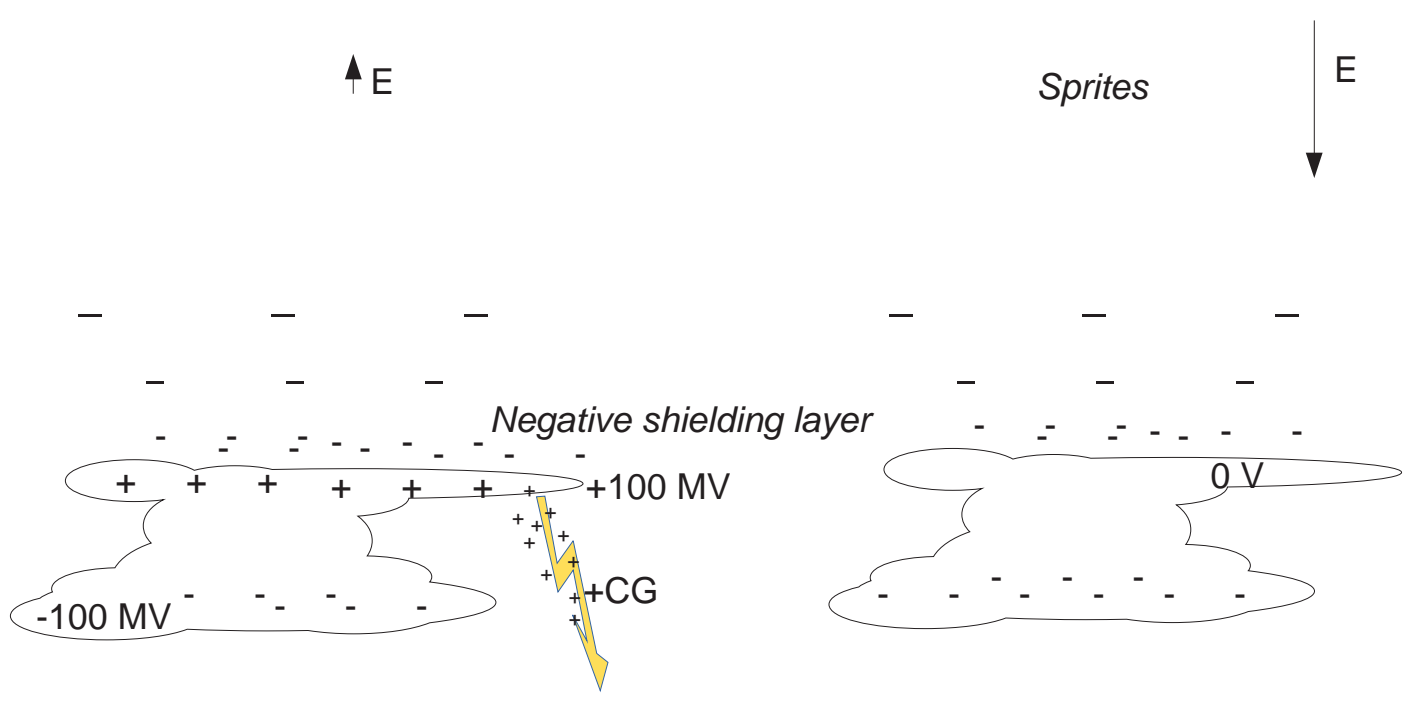

Ground: 0 V

Fig. 2. Schematic illustration of the mechanism of production of quasi-static electric field after + CG. Adapted from Pasko et al. (1997). Notice that vertical scale should not be treated as realistic.

The "amount of charge lowered to the ground multiplied by the distance between the charge reservoir and the ground" is called the charge moment change (CMC) (Neubert et al., 2008). ELF data can serve to estimate the CMC of the sprite-triggering discharge. It is an important factor for estimating probability of sprite production by a lightning (Neubert et al., 2008). For a sprite to be initiated, the charge moment change of the causative $+\mathrm{CG}$ must be of the order of 
few hundreds of $\mathrm{C} \mathrm{km}$; however, values as small as $120 \mathrm{C} \mathrm{km}$ can also produce a faint sprite (Cummer, 2003). Other values given in the literature for sprite-producing +CGs are 200-1,100 $\mathrm{C} \mathrm{km}$ (Bell et al., 1998), 150-1,100 C km (Cummer and Stanley, 1999), whereas daytime sprites have been observed to be initialized by $\mathrm{CMC}$ as high as 6,100 $\mathrm{C} \mathrm{km} \mathrm{(Stanley} \mathrm{et} \mathrm{al.,} \mathrm{2000).} \mathrm{If}$ there existed a model of relating causative lightning current and CMC to whistlers' strength, this could serve for investigation of sprites from satellite whistler detections.

\section{SPRITE AS A STREAMER DISCHARGE}

Sprites, just as lightnings, can be generalized as breakdown discharges in a gaseous medium. Electric breakdown is generally defined as a "process of transformation of a non-conducting material into a conductor as a result of applying to it a sufficiently strong field" (Raizer, 1991, p. 128). The breakdown threshold is $\quad E_{k} \approx 32 \mathrm{kVcm}^{-1}$ at ground level and is proportional to air density (it lowers with altitude) (Surkov and Hayakawa, 2012).

In a gas with applied electric field, there are two processes: ionization, which leads to increase in the number of free electrons in the environment, and deionization, which leads to reducing that number. Breakdown threshold is defined as a field at which ionization rate reaches the level of deionization and these two are equal. The breakdown starts as follows: first, free electron starts an avalanche because of collisional ionization of other particles. The more free electrons are in the gas, the larger avalanche grows, accelerated by the E field. When the number of electrons in the avalanche head reaches certain amount, the avalanche turns to a streamer. If the gap between two field-applying conductors is small enough, streamer can become a spark ending with the complete breakdown of the gap (Cooray, 2014, p. 60).

Although streamer is generated in the field above the breakdown threshold, once it is generated, it can propagate through the regions where the surrounding field is much lower than $E_{k}$. The charge density in streamer head is so large that it produces electric field of value 4-7 $E_{k}$, which allows for accelerating electrons to energies causing enhanced ionization and progressive movement of the streamer. Typical streamer is a self-propagating filament of lowconductive plasma with a velocity of $10^{2}-10^{4} \mathrm{~km} \mathrm{~s}^{-1}$ (Surkov and Hayakawa, 2012).

The charge in streamer's head can be either positive or negative. Streamers with positive charge move toward cathode and are called positive streamers; those that contain negative charge in their head are called negative streamers and move toward the anode. Negative streamers propagate because of ejection of electrons from their heads. Positive ones propagate because of injection of avalanching surrounding electrons (Surkov and Hayakawa, 2012). For more details on the formation of streamers and their characteristics, refer to Cooray (2014) and Raizer (1991).

From the ELF measurements and optical observation, it was shown that sprite streamers produce measurable currents in the ionosphere (Füllekrug et al., 2001). The radiation was theoretically explained based on a simplified moving capacitor plates model (Pasko et al., 1998) and a streamer model (Qin et al., 2012). The latter model showed how streamers can produce different radio frequencies depending on their altitude, from the ELF up to low frequencies (LFs; 10-300 kHz). The LF emission have been previously assumed to be produced by relativistic electron avalanches at sprites' altitudes by Füllekrug et al. (2010), but it could be explained at least partially by Qin's streamer model.

\section{SPRITES AND TERRESTRIAL GAMMA-RAY FLASHES}

Terrestrial gamma-ray flashes (TGFs) were discovered by an accident by the Burst and Transient Source Experiment (BATSE) on board Compton Gamma-Ray Observatory that was 
designed to measure the radiation coming from space, not the Earth itself. The results were published in 1994; however, the first observation came from 1991 (Fishman et al., 1994). For long time, it was supposed that the emissions are caused by sprites in the mesosphere and the possibility of generation at lower altitude was excluded. It was believed to be so because of too strong atmosphere attenuation for low-produced TGFs, preventing measurements from space (Dwyer et al., 2012). Later on, measurements made by the Reuven Ramaty High Energy Solar Spectroscopic Imager (RHESSI) showed that the altitude of production lays below $20 \mathrm{~km}$ and the consensus has changed (Dwyer et al., 2012).

The Astrorivelatore Gamma a Immagini LEggaro (AGILE) satellite has measured TGFs of energy up to $40 \mathrm{MeV}$ (Marisaldi et al., 2010) and the duration of several tens of microseconds (Marisaldi et al., 2014). Other important missions for measuring TGFs include Fermi (Roberts et al., 2018) and ASIM (Østgaard et al., 2019).

TGFs from satellite observations can be associated with the triggering lightnings, thanks to the World Wide Lightning Location Network (WWLLN). Using Fermi Gamma-ray Bursts Monitor (GBM) catalog of TGFs, it was shown that the shorter event have higher probability of association - events of shorter duration $(<90 \mu \mathrm{s})$ are associated with lightnings in $\sim 50 \%$ cases, whereas for the longest TGFs $(>210 \mu \mathrm{s})$, the association rate is $\sim 10 \%$ (Connaughton et al., 2013).

The leading theory explaining the acceleration of particles during TGFs is relativistic runaway electron avalanche (RREA), which will be described in the next section. It used to be believed that RREA occurs in sprites and that it may cause TGFs; however, no direct proofs of correlation of sprites and TGFs have been found yet. What is more, electron avalanches at sprite altitudes would be led by magnetic field lines and this behavior have not been observed during the occurrence of sprite (Dwyer et al., 2012; Dwyer and Uman, 2014). Füllekrug et al. (2010, 2011) claimed that they have found radio signatures of high-altitude RREAs in 40 - to $400-\mathrm{kHz}$ (LF) range, after sprite-producing lightnings; some were accompanied by sprite discharges. However, it is possible that these emissions were caused by typical lightning processes of spritetriggering lightnings (Dwyer et al., 2012) or by sprites streamers (Qin et al., 2012), without the involvement of a high-altitude RREA. LF signals were already found to accompany TGFs related to intracloud flashes (ICs), and, recently, VHF radio signatures have been found during the lightning-induced TGF events too (Lyu et al., 2018).

Although the proofs for sprite-triggered TGFs are not widely accepted, theoretically, it is possible that quasi-electrostatic field existing during the initiation of sprite could lead to the production of runaway electrons (Dwyer et al., 2012; Kudintseva et al., 2010). The theory standing behind sprite-associated runaway electron avalanche can be found in Surkov and Hayakawa (2012).

Recently, more attention has been paid to associating TGFs and other type of TLEs-elves. The modeling found that energetic in-cloud pulses (EIPs) associated with some TGFs can also cause elves. For longer EIPs, elve doublets and multiplets can appear. TGFs of shorter duration should have accompanying elves more probably as their source currents vary more rapidly (Liu et al., 2017). Regarding elves' abundance, the data from ISUAL experiment showed that elves are 9 times more common than sprites (Chen et al., 2008).

\section{RUNAWAY ELECTRONS AND RUNAWAY RELATIVISTIC ELECTRON AVALANCHE (RREA)}

One of the explanations of sprites' generation is due to a RREA. It serves as hypothetical mechanism for sprite's optical emission and needed ionization (Surkov and Hayakawa, 2012), 
but as it has been mentioned in the previous section, it is disregarded by some scientists (Dwyer et al., 2012).

Runaway electrons were defined as electrons that do not circulate through all the energy states available to them at certain $E / N$ but, on an average, move toward high-energy states, where $E$ is the electric field and $N$ is the number density of neutrals (Bell et al., 1995; Lehtinen et al., 1996; Roussel-Dupré et al., 1998; Taranenko and Roussel-Dupré, 1996; Yukhimuk et al., 1998). Becoming runaway is possible because of the fact that friction force, when an energetic electron passes the air, starts to fall for electrons of the energies $\varepsilon>150 \mathrm{eV}$ (the explanation here is given after a detailed description in Dwyer and Uman, (2014) and Surkov and Hayakawa (2012)).

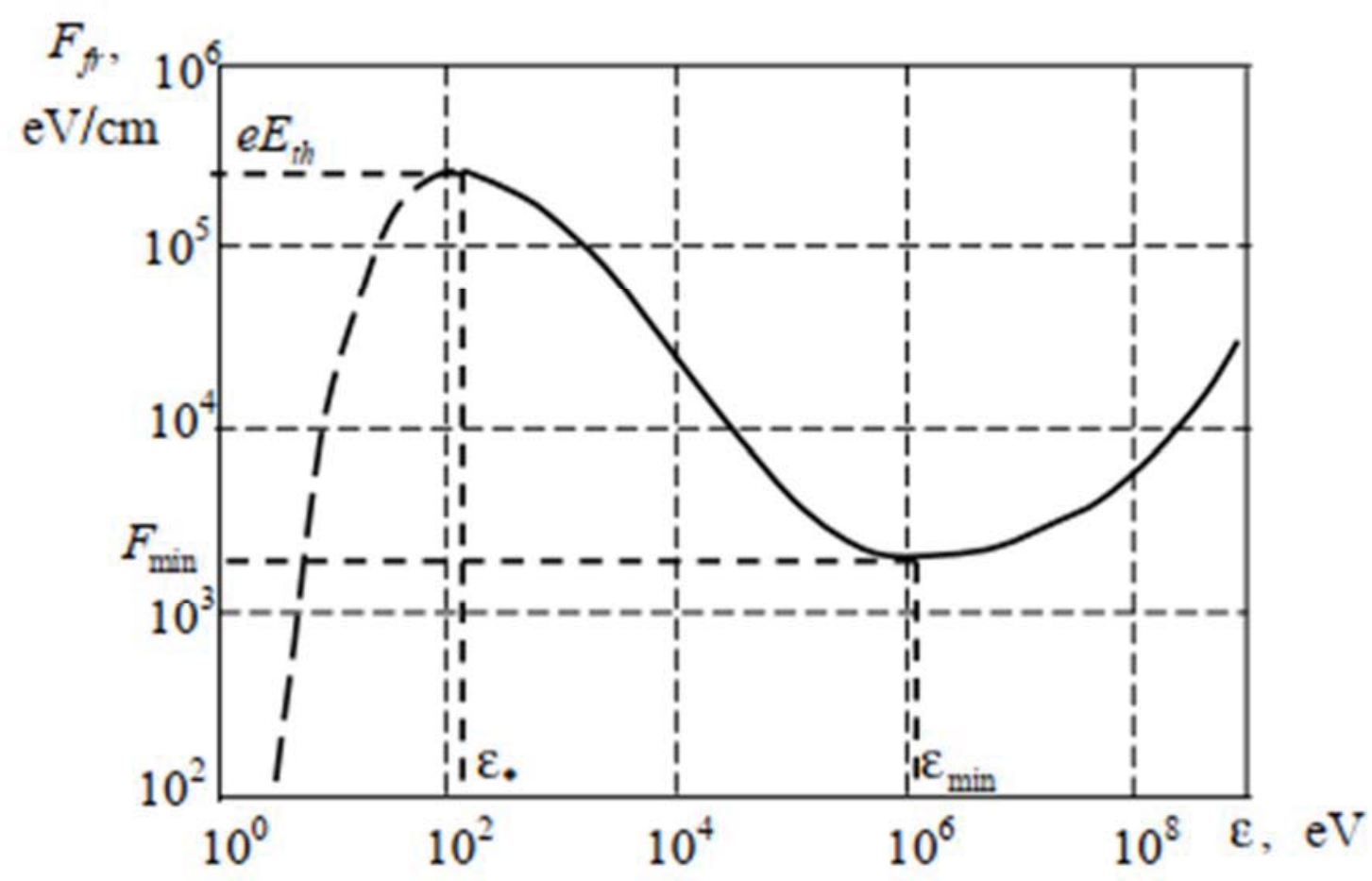

Fig. 3. A schematic plot of dynamical friction force of electrons in the air versus electron kinetic energy. From Surkov and Hayakawa (2012).

When constant electric field $E$ acts on the electron with the force $e E$, the momentum equation in 1D (legitimate for the electrons above $50 \mathrm{eV}$ (Pasko, 2006)), which is given as follows:

$$
\frac{\mathrm{dp}}{\mathrm{dt}}=\mathrm{eE}-F_{\mathrm{fr}}(\varepsilon)
$$

Figure 3 shows friction force experienced by a free electron according to its energy. Below $\sim 150 \mathrm{eV}$, the ionization and excitation of different electronic states of $\mathrm{N}_{2}$ and $\mathrm{O}_{2}$ put high impact on the electron, and when its energy rises, the friction rises too. Above that energy, however, the friction starts to decrease when the electron's energy rises, so that the electron can move toward higher-energy state because of the influence of the electric field. This is because the scattering of electrons with energies higher than $\sim 150 \mathrm{eV}$ is governed by Coulomb's law for fast-moving electron through the air. It is related to Rutheford's (1911) experiment, which showed that fast electrons interact with other nuclei and electrons of neutral matter as if they were all free charged particles (Pasko, 2006). Coulomb scattering has a cross section of $\sigma \sim \frac{1}{\varepsilon^{2}}$. In non-relativistic regime, this gives the friction force $F_{\mathrm{fr}} \sim \mathrm{N} \varepsilon \sigma \sim \frac{1}{\varepsilon^{2}}$ 
(Surkov and Hayakawa, 2012). This relation ends at electron's energies above $\sim 1.4 \mathrm{MeV}$ because of the relativistic effects when the friction forces reach minimum $\mathrm{F}_{\min }$ and then start to grow logarithmically (Rutheford, 1911).

To sum up, for the electron to become runaway, it is possible if its pushing force $e E$ in electric field $E$ is larger than the friction force. If the $E$ field is larger than $E_{\text {th }}=2.6 \cdot 10^{7} \mathrm{~V} / \mathrm{m}$, then all electrons become runaway as $e E$ th always overcomes the friction (see Figure 3 ). This situation is called "thermal runaway" or "cold runaway" (Dwyer and Uman, 2014).

According to Surkov (2012), in electron energy in the range of $\sim 150 \mathrm{eV}$ to $\sim 1.4 \mathrm{MeV}$ (slope down at Figure 3), when the increase in the momentum because of the $E$ field is not accompanied by increased friction because of scattering through the air, we can derive critical field for runaway electrons from Bethe's formula for electron friction force (Bethe, 1930), stating that $E_{c}=\frac{F_{\min }}{e}=\frac{4 \pi \mathrm{e}^{3} \mathrm{ZNa}}{m_{e} c^{2}}$, where $Z$ is the mean number of electrons in molecule, $N$ is the numbers density of neutrals in the air, $a \approx 11$ is a constant derived from Bethe's formula, $m_{e}$ is the mass of an electron, and $c$ is the speed of light. In this case, electrons laying in some energy range gain more and more energy from electric field until the friction starts growing again because of the relativistic effects for electrons above $\sim 1.4 \mathrm{MeV}$ (Gurevich and Zybin, 2001). Constraint for the electron minimum energy to become runaway in surrounding field $E$ can be given as

$$
\varepsilon>\varepsilon_{c} \approx \frac{E_{c}}{2 E} m_{e} c^{2} .
$$

Minimum field for the runaway is dependent on the number density of neutrals and thus on height. This dependency is approximated as $E_{c}=$ $2.16 \exp (-z / h) \cdot 10^{5} \mathrm{~V} / \mathrm{m}$, where $\mathrm{h} \approx 8-10 \mathrm{~km}$ (Surkov and Hayakawa, 2012). Runaway threshold $E_{c}$ is at least an order of magnitude smaller than the conventional breakdown threshold $E_{k}$. At ground level, $\quad E_{c}=2.16 \cdot 10^{5} \mathrm{~V} / \mathrm{m}$, whereas the conventional breakdown threshold (occurs without the presence of the energetic "seed" electrons) is $E_{k}=3.2 \cdot 10^{6} \mathrm{~V} / \mathrm{m}$ and thermal runaway threshold is $E_{\mathrm{th}}=2.6 \cdot 10^{7} \mathrm{~V} / \mathrm{m}$ (Surkov and Hayakawa, 2012). Each of the thresholds is approximately an order of magnitude larger than the previous one. It is legitimate to assume that thermal threshold may be exceeded in streamers' tips in sprites and lightnings (Moss et al., 2006) and in sparks at atmospheric pressure (Oreshkin et al., 2012).

For the electron to run away in the field $E_{c}<E<E_{t h}$, the electron must be highly energetic from the moment it enters the electric field. There are two hypothetical sources of these energetic "seed" electrons: radioactive decay in the atmosphere and cosmic rays; however, for the initiation of sprites, cosmic rays and extensive air showers are the most probable ones (Colman et al., 2010).

Theory of runaway electrons was given at first by Wilson in 1925 (Wilson, 1925). It was later extended into RREA theory, described at first by Gurevich et al. (1992). RREA describes how Møller scattering between energetic runaway electrons and electrons in the air can lead to an avalanche. In an avalanche, few "seed" or "primary" electrons produce large amount of the so-called "secondary" electrons. The latter ones are less energetic, but some of them have energy $\varepsilon>\varepsilon_{c}$, and they also become runaway because of the E field that accelerates them. They also add to the ionization and start an exponentially increasing avalanche of runaway electrons. The avalanche is a source of X-rays and gamma-rays when relativistic particles decelerate and produce the radiation because of bremsstrahlung (Dwyer and Uman, 2014; Surkov and Hayakawa, 2012).

RREA is a name given by Dwyer in his extension of Gurevich's theory (Gurevich preferred the name "runaway breakdown"; Dwyer and Babich, 2012). Dwyer's contribution lead to the 
understanding of how runaway avalanches can occur at low altitudes and how intracloud lightnings can produce TGFs. Except from Møller scattering, he included production of positrons and energetic photons because of scattering that leads to positive feedback in the process that greatly increases its efficiency. Interested reader can seek more information in Dwyer et al. (2012) and Dwyer and Uman (2014).

\section{SOURCES OF SEED RUNAWAY ELECTRONS}

Seed electrons are related either to cosmic rays or to radioactive decay in air. Cosmic rays were discovered by Victor Hess (1912) during his balloon-borne measurements of the ionization of air in 1911 and 1912. He discovered that the ionization does not decrease essentially with the altitude, even during a partial solar eclipse. What is more, from some height, it starts to increase, what proved the extra-terrestrial and extra-solar source of ionization (Carlson et al., 2008; Surkov and Hayakawa, 2012). The very phrase "cosmic rays" is some sort of a misnomer because now it describes massive particles (mostly protons) that come from the outer space and not the electromagnetic radiation (which is rather called X-rays or gamma-rays). However, because of historical reasons, this name is still used in the literature.

Highly energetic cosmic rays of energies greater than few gigaelectronvolts and higher are well documented in the literature. They are capable of producing the so-called extensive air showers (EAS) - a cascade of secondary particles initiated by one primary cosmic ray. EAS consists of typically $89 \%$ of photons, $10 \%$ of electrons (energies up to $30 \mathrm{MeV}$ ), and $1 \%$ of other particles. These electrons are key for initiating runaway breakdown-they become the seed electrons of the avalanche (Nagano and Watson, 2000).

Sprites are associated with strong +CG discharges that invert the normally occurring E field so that its vector points from the ionosphere to the cloud (as was mentioned in Section 5). We should note that this quasi-electrostatic field acts on the seed electrons that run along cosmic ray (that is moving toward the ground) by decreasing - not increasing - their energy with $e E$ force. In such conditions, the runaway breakdown could not occur. A probable explanation of the actual occurrence, basing on runaway avalanche hypothesis, is that the seed electrons reverse their movement by interacting with nuclei of air particles. At such collision, the scattering occurs in all directions and eventually some of the scattered electrons with high enough energy can turn into runaway avalanche moving upward (downward directed E field will accelerate upward moving electrons; Carlson et al., 2008; Surkov and Hayakawa, 2012).

Carlson et al. (2008) have been modeling the number of seed electrons produced by cosmic rays using the Monte Carlo method. Their outcomes cover the altitudes of 1-30 km above ground level, which is too low for sprite's initiation; however, their computations proved significant number of downward-directed seed electrons at $\sim 30 \mathrm{~km}$ with energies $1 \mathrm{MeV}$ (around $10^{3} \mathrm{~m}^{-2} \mathrm{~s}^{-1}$ ).

Paiva et al. (2009) considered different model of seed electron production because of radioactive decay of muon that forms after the interaction of cosmic rays and air.

\section{MICROMETEOROIDS}

Zabotin and Wright (2001) have shown that small conducting particles of meteoric origin may play important role in the formation of sprites and proved that the presence of meteoric dust in mesosphere and stratosphere is relatively high.

Considering the composition of the micrometeoroids being predominantly metallic, the dust is treated as conductor. Thus, in the presence of external electric field $E$, particles acquire the induced dipole moment that amplifies the field. The effect is even more pronounced, whereas 
the micrometeoroids contain microscopic poles on their surface. Such a condition is fulfilled in our case (Bugaev et al., 1975) and leads to enhancing the field because these microscopic poles or "microspires" are source of electrons and ions because of chain reaction of "cathode instability," auto-emission and explosive emission (Raizer, 1991). By this mechanism, one micrometeoroid can create a plasma cloud with a radius of 10-30 m and an electron density of $10^{6} \mathrm{~cm}^{-3}$, which can possibly develop a streamer without the phase of electron avalanche. The micrometeoroids may also be responsible for branching of streamers when the original streamer meets plasma cloud emitted from a meteoroid particle and for the enhancements of luminosity at streamers bifurcation points because of explosions of the meteoric dust (Zabotin and Wright, 2001).

Wescott et al. (2001) argued that while sprite halo occurs directly above the causative $+\mathrm{CG}$ lightning, the very sprites (if they show up after the halo) are mostly displaced from that direction. They stated that only meteoric dust is a good candidate for a trigger capable of explaining this displacement. The authors stated that ionization because of cosmic rays is too much spread to provide the explanation for isolated, sporadic events such as sprites, whereas it still provides a steady background ionization.

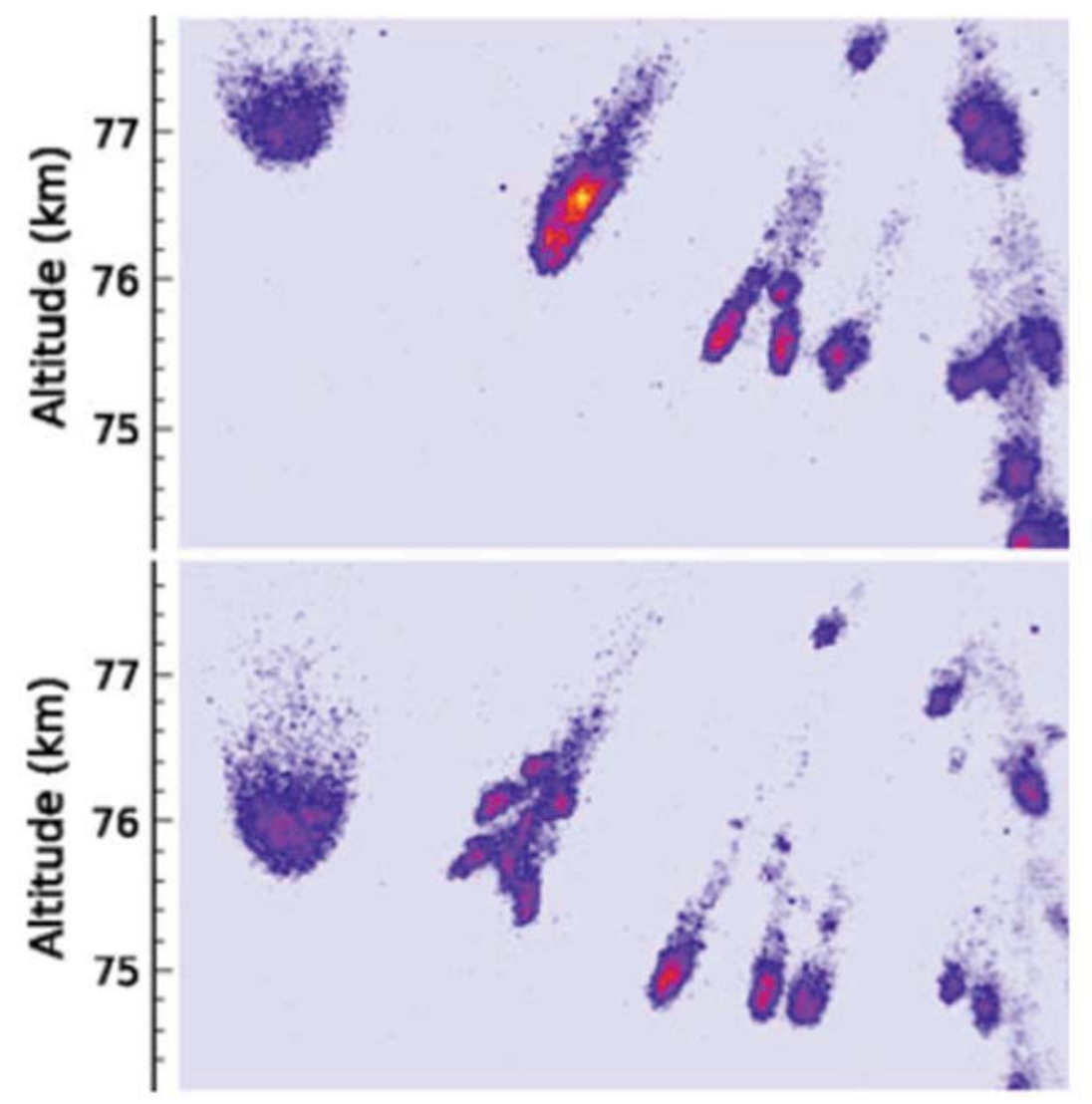

Fig. 4. Two successive frames recorded at 16,000 fps showing streamer splitting. The field of view is $1.3^{\circ} \times 0.6^{\circ}$. The images have been color coded to enhance details. The streamer at center left splits into at least 8 sub-streamers within $62.5 \mu \mathrm{s}$. The images were recorded from Langmuir Laboratory, NM, on July 15, 2010 at 07:06:09 UT. Image taken from StenbaekNielsen et al. (2013)

\section{SUBTLE STRUCTURE OF SPRITES}

Telescopic imaging from the ground reached very precise level with good spatial resolution and temporal accuracy as high as 32,000 fps. Many sprite observations have shown filamentary, 
"tendril-like" structures interpreted as streamers (Cummer, Jaugey, et al., 2006; Gerken and Inan, 2002; Marshall and Inan, 2005; Stenbaek-Nielsen et al., 2013). In some cases, the sensitivity of the apparatus leads to imaging of structures as narrow as the lower limit of the resolution-10-20 m (Marshall and Inan, 2005). Typically, sprite streamers, however, are less than a few hundred meters in diameter (Stenbaek-Nielsen et al., 2013). It was shown that wider streamers move faster and the relation of the diameter to velocity is roughly linear (Kammae et al., 2012).

Streamers often split what is a behavior exhibited not only by sprites but also in laboratory experiments (Kochkin et al., 2016). Phenomenon of sprite splitting (see Figure 4) is easier to examine for downward propagating streamers because they more often appear on dark background. Before the split, a streamer glows brighter and grows wider. Streamers that split are, on an average, 4 times more luminous than those that do not split and their median width is, on an average, $\sim 400 \mathrm{~m}$ in comparison to $\sim 200 \mathrm{~m}$ for non-splitting ones. This could indicate that there is a minimal width of streamer that splits. Sprite streamers can split into 2-10 substreamers, whereas laboratory streamers split mostly into 2 and, rarely, into 3 sub-streamers (Stenbaek-Nielsen et al., 2013).

Ebert et al. (2010) compared the results from laboratory streamers measurements with sprites observations. They suggested that there may be a general minimal diameter for sprite streamer, around $20 \mathrm{~m}$ because there is a minimal diameter for laboratory streamer too.

Ground-based experiments can help understanding streamer branching. For example, using data from Briels et al. (2008), it was measured that for streamer of diameter $d$, branching occurs after path $D$ in relation: $D / \mathrm{d}=11 \pm 4$ for pressure $0.1-1$ bar. The relations between laboratory streamers and mesospheric ones are governed by similarity laws, and in most cases, molecule number density $N$ is the most important scaling factor. More details on scaling factors can be found in Ebert et al. (2010) and Pasko (2006).

Streamers have been successfully modeled by several groups. One of the first working models of sprite streamers was that of Pasko et al. (1997) that later led to the development of a successful model that included photoionization (Liu and Pasko, 2004). The latter model allowed for the hypothesis that streamer formation in sub-breakdown conditions is possible because of large inhomogeneities such as ionization columns (Kosar et al., 2012; Liu et al., 2012) or halo resembling patches (Kosar et al., 2013). As it was mentioned in cited works, those inhomogeneities are to have few orders of magnitude larger plasma density and can be caused by lightning-related processes, gravity waves, or micrometeoroids. They also explained why many sprites consist only of downward-propagating positive streamers without the appearance of upward-propagating streamers too (or with their appearance, but only after some delay and from already existing structures; Cummer, Jaugey, et al., 2006; Stenbaek-Nielsen and McHarg, 2008). It is supposed to be so because of the lower voltage threshold for the formation of positive streamers than for the negative ones (Liu et al., 2012). That threshold was also noticed by Briels et al. (2008) in laboratory experiments. Later on, smaller, 1-km-scale inhomogeneities were also taken into account for hypothetical reason of formation of long-delayed sprites (Liu et al., 2015).

Another successful sprite streamer model was made by Luque and Ebert (2009), based on the existing model for laboratory streamers (Ebert et al., 2006). In their work, the formation of a streamer is caused by downward-propagating screening-ionization wave caused by a charge moment change of $\sim 1,500 \mathrm{C} \mathrm{km}$. This wave is sometimes visible as luminous halo. The authors state that probably a horizontal inhomogeneity of electron or air density is needed to destabilize the wave and create sprite streamers. 
In many cases, there is no halo visible before the occurrence of a streamer, especially for long-delayed sprites. This could lead to the assumption that no large inhomogeneity was present at sprite initiation. However, this could also be caused by low sensitivity of the apparatus (Stenbaek-Nielsen et al., 2013).

The development of a streamer from halo is shown in Figure 5. On this picture, the main halo fades away, but streamers develop from a remaining structure. This remnant luminosity may by the ionization wave proposed by Luque and Ebert (Stenbaek-Nielsen et al., 2013). 
Recently, theoretical study on instabilities that could lead to sprite filamentary structure was provided in Błęcki and Mizerski (2018). The authors have found an instability that leads to enhanced plasma density distribution in the form of stripes aligned with electric field. This could serve for explaining structure of streamers in sprites.

Fig. 5. Streamer development in the event on August 27, 2009, at 09:15:23 UT. Top image, A, has the elve across the center part of the image, and the halo is just entering the field from above. Image $B$ shows the halo with considerable spatial structure. Image $\mathrm{C}$ shows the early streamers, and D shows the central streamer with glow from upward-propagating streamers. This event is an example of an event that is a combination of multiple Csprites and carrots. Panel E shows a 2.5-ms image time series with the halo streamer development. The time series is formed from the image sections outlined by the white box in images A-C (Image D is after the end of the time series). The streamer is seen to form from structure in the halo descending with the halo and forms after the main halo has faded. The scale on the left is the elevation angle (in degrees) and on the right is the altitude (in $\mathrm{km}$ ), assuming that the sprite is at a distance of the causal lightning discharge. Taken from Stenbaek-Nielsen (2013)

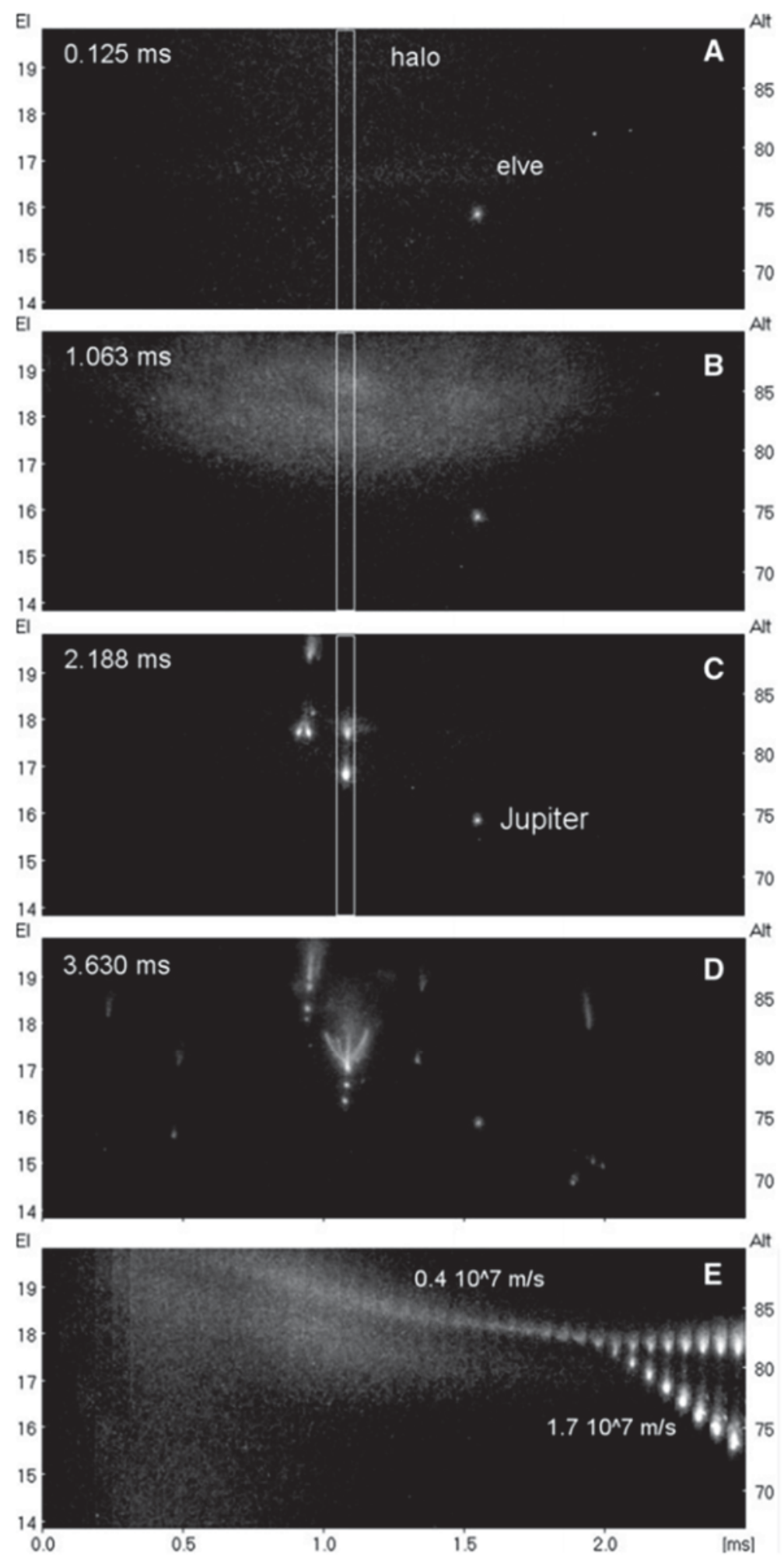




\section{TARANIS SCIENTIFIC PAYLOAD}

TARANIS is a French Space Agency's (CNES) mission dedicated to examining TLEs and TGFs as well as other effects related to energy transfer between the atmosphere of Earth, ionosphere, and magnetosphere (Blanc et al., 2007).

The satellite is planned to be launched in 2020 . It will fly at $98^{\circ}$ polar low Earth orbit at $\sim 700 \mathrm{~km}$ and will be sun-synchronized with 2 hours drift from local time per year. Being launched at $10 \mathrm{PM}$ local time in 2 years, it will cover the period 10 to 2 both before midday and after (10-2 AM and 10-2 PM). Owing to power-budget limitations, instruments will operate only between $60^{\circ} \mathrm{S}$ and $60^{\circ} \mathrm{N}$ geographic latitude, however, this covers most of the area where storms occur and TLEs and TGFs are expected (Lefeuvre et al., 2008).

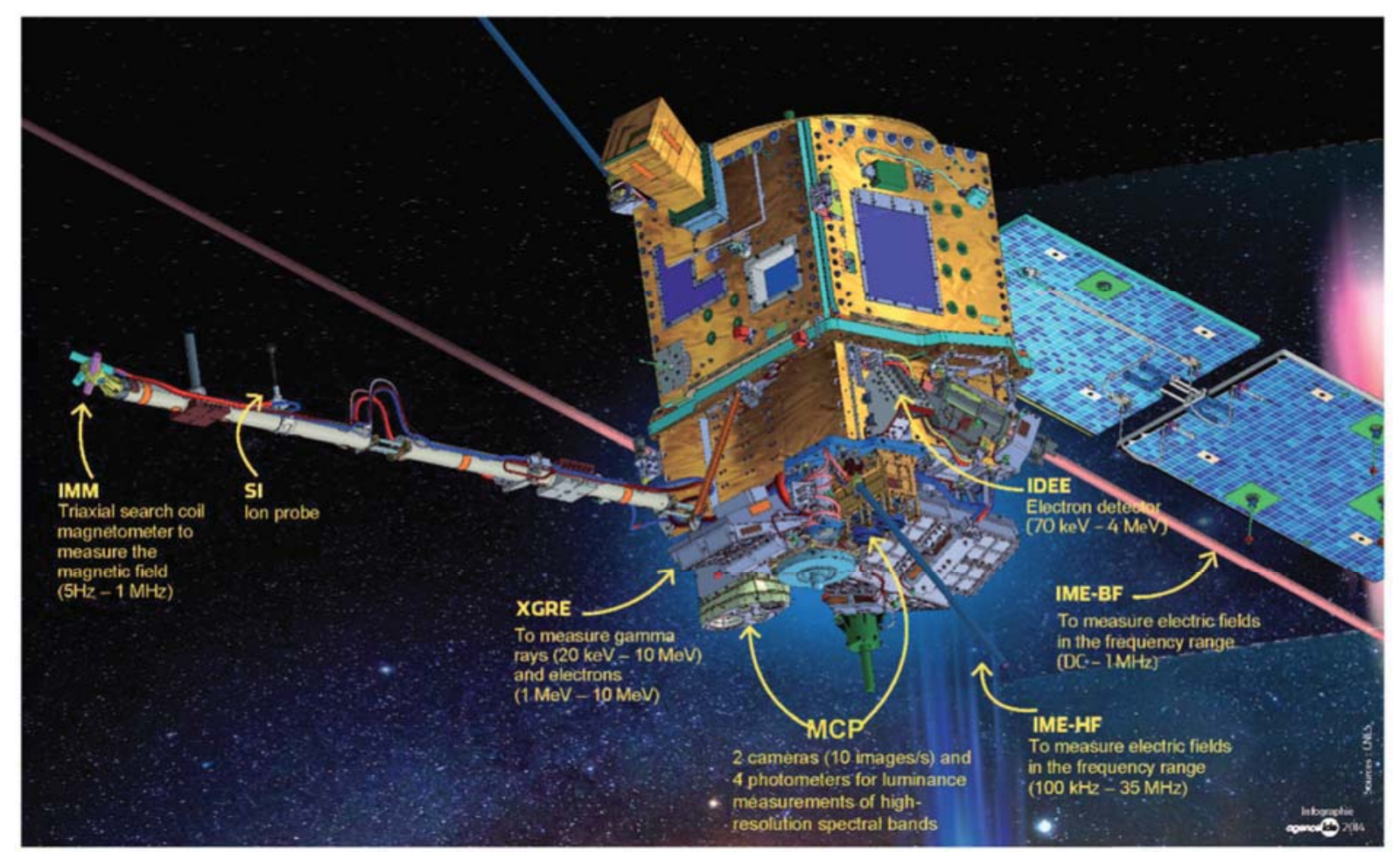

Fig. 6. TARANIS satellite systems. Courtesy of CNES.

Main topics of TARANIS mission are (Blanc et al., 2007; Lefeuvre et al., 2008):

- TLEs and TGFs observations

- Environmental conditions of TLEs and TGFs, such as triggering lightnings, correlation with cosmic rays, micrometeoroids, volcanoes, structure of atmosphere

- Transfers of energy between atmosphere, ionosphere, and radiation belts

- Provide inputs for modeling TLEs and TGFs generation mechanisms

- Provide inputs for modeling large-scale effects on ionosphere and global electric circuit because of TLEs, TGFs, and bursts of precipitated or accelerated electrons.

The scientific payload includes

- Micro Cameras and Photometers

Micro cameras and photometers (MCP) consists of 2 microcameras and 4 photometers; it alerts the TARANIS system of TLE occurrence. Both cameras have the same hardware but are filtered to pass different bands of light. The first camera is designed to detect sprites with filter passing $\mathrm{N}_{2} 1 \mathrm{P}, 762 \mathrm{~nm}$ band, strongest emission band of sprites. The contamination by the $\mathrm{O}_{2}$ band at $761.9 \mathrm{~nm}$ is prevented by the fact that $\mathrm{O}_{2}$ density is much higher in the troposphere than in the ionosphere and the emission will be strongly attenuated at the altitude of TARANIS. The second camera is designed for 
detecting lightnings with a filter focused on $777 \mathrm{~nm}$. Cameras' sample size is about 1 $\mathrm{km}^{2}$ at nadir. Low spatial resolution is sufficient for statistical measurements and measuring emission rates, whereas high-resolution measurements can be provided from ground systems.

Photometers will work in Lyman-Birge-Hopfield (LBH) UV band at 160-260 nm, $\mathrm{N}_{2} 2 \mathrm{P}$ band at $337 \pm 5 \mathrm{~nm}$, and $\mathrm{N}_{2} 1 \mathrm{P}$ at $762 \pm 5 \mathrm{~nm}$ and $600-900 \mathrm{~nm}$. See Section 3 for the description of these bands (Blanc et al., 2012).

- Instrument for Electric field Measurements-Low Frequency (IME-BF)

The instrument covers the range of LFs and medium frequencies ( $0 \mathrm{~Hz}$ to $1 \mathrm{MHz})$. It can be used for observing emissions from $0^{+}$whistlers (whistler that has not yet been reflected by the magnetic mirror, see Section 4) that were produced by causative lightnings of the TLE or TGF events. This can be especially useful for recording intracloud discharges that often cannot be registered by ground-based systems. It can also be used for estimating plasma parameters and monitoring electromagnetic surrounding of the satellite. It probably could be used for monitoring electron and runaway electron beams. The instrument is equipped with ion probe too (Lefeuvre et al., 2008).

- Instrument for Electric field Measurements-High Frequency (IME-HF)

The instrument covers the frequencies $100 \mathrm{kHz}$ to $35 \mathrm{MHz}$. At highest frequencies, which are weakly attenuated by the ionosphere, its goal is to gather signatures of TLEs, TGFs, lightning flashes, and narrow bipolar events. At lower frequencies, below $1 \mathrm{MHz}$, it overlaps with IME-BF measurements, giving the possibility to tell the polarization characteristics and identify wave propagation modes ( $\mathrm{O}$ or $\mathrm{X})$. In full band, it could serve for monitoring the TIPPs (see Section 4) and man-made emission, giving opportunity to estimate local plasma frequency from cutoff frequency (similar to that with the use of an ionosonde; Lefeuvre et al., 2008).

- Instrument for Magnetic Measurements (IMM)

The instrument measures magnetic flux in the range from few hertz to $1 \mathrm{MHz}$. It has got two functions: at VLF (below $20 \mathrm{kHz}$ ), measuring propagation characteristics of the wave such as polarization and direction; at whole range, to complete the data from IME$\mathrm{BF}$, to distinguish electrostatic and electromagnetic waves, and to provide propagation characteristics. Data analyzer will include IME-BF data for $0^{+}$whistler detection that will serve for lightning-tracing purposes (Lefeuvre et al., 2008).

- X-ray, Gamma-ray, and Relativistic Electron Experiment (XGRE)

XGRE, $3 \times 300 \mathrm{~cm}^{2} \mathrm{CsI}(\mathrm{Na})$ scintillators, can detect photons $(20 \mathrm{keV}$ to $10 \mathrm{MeV})$ and energetic electrons/positrons (1-10 MeV) related to TGF. It is able to quantify the total energy of the event, altitude of the generation together with its time and geographic coordinates. The instrument will also be able to distinguish X-ray and gamma-ray photons from energetic electrons/positrons (Sarria et al., 2017).

- Instrument for Detection of Energetic Electrons

Instrument for detection of energetic electrons (IDEE) will provide high-resolution spectra of energetic electrons ( $80 \mathrm{keV}$ to $5 \mathrm{MeV})$ and their pitch angles. It is focused on lightning-induced electron precipitations (LEPs) and terrestrial electron beams (TEBs) associated with TGFs. It was designed to detect even very short transients $(<10 \mathrm{~ms})$ with small fluence (Sarria et al., 2017).

- Multi Experiment Interface Controller Equipment

All the data will be interfaced by the Multi Experiment Interface Controller equipment (MEXIC), a device responsible for providing the energy supply and receiving, managing, and transferring the data. MEXIC was built with the participation of Space Research Centre of the Polish Academy of Sciences (Lefeuvre et al., 2008). 
Table 1. TARANIS scientific payload.

\begin{tabular}{|c|l|}
\hline Instrument & \multicolumn{1}{|c|}{ Instrument description } \\
\hline MCP & $\begin{array}{l}2 \text { microcameras }(762 \text { and } 777 \mathrm{~nm}) ; 4 \text { photometers }(160-260,337 \pm 5, \\
762 \pm 5, \text { and } 600-900 \mathrm{~nm})\end{array}$ \\
\hline IME-BF & LF electric field measurement (DC to 1MHz); ion probe \\
\hline IME-HF & HF/VHF electric field measurement $(100 \mathrm{kHz}$ to $35 \mathrm{MHz})$ \\
\hline IMM & $\begin{array}{l}\text { Magnetic field measurement in VLF }(5 \mathrm{~Hz} \text { to } 20 \mathrm{kHz}) \text { and } \mathrm{MF}(10 \mathrm{kHz} \\
\text { to 1 MHz); } 0^{+} \text {whistlers detector }\end{array}$ \\
\hline XGRE & $\begin{array}{l}\text { Photons detection in the } 20-\mathrm{keV} \text { to } 10-\mathrm{MeV} \text { range and energetic } \\
\text { electrons/positrons detection in the } 1-\text { to } 10-\mathrm{MeV} \text { range }\end{array}$ \\
\hline IDEE & Energetic electrons detection $(80 \mathrm{keV}$ to $5 \mathrm{MeV})$ \\
\hline MEXIC & Power supply and data management \\
\hline
\end{tabular}

\section{CONCLUSIONS}

TARANIS is the first satellite that will cover such wide measurements of the TLEs, examining simultaneously the electromagnetic radiation, optics, and particles. Another CNES mission, DEMETER, carried similar electromagnetic equipment that gathered useful data about thunderstorms and TLEs (see, e.g., Parrot et al., 2008). Recently, many spacecrafts related to examining thunderstorms were sent or will be sent in the nearest future-American GOES-R, European MTG with their lightning imagers; TARANIS is sent as a part of cooperation that include ASIM module and Lightning Imaging Sensor (LIS) onboard the ISS; Russian Chibis$\mathrm{AI}$ is to be soon released. By the cooperation of different groups of scientists, interesting outcomes are expected.

The EM signal and particles transfer is attenuated by the atmosphere. Researches have shown that $100-\mathrm{kHz}$ radio signal is attenuated by around $40 \mathrm{~dB}$ when passing the ionosphere (Füllekrug et al., 2009), but models suggest that much of LF emissions should be measurable at satellite altitudes (Füllekrug, Hanuise, et al., 2011).

Regarding TGFs, Xu et al. (2017) claimed that when a TGF travels through the atmosphere from the altitude it was produced, it excites electrons because of Compton scattering and photoelectric absorption. These TGF-induced electrons should produce optical emission in $\mathrm{N}_{2} 2 \mathrm{P}(337 \mathrm{~nm})$ and $\mathrm{N}_{2} 1 \mathrm{P}$ bands that would spread above cloud tops $(12-15 \mathrm{~km})$ and be visible from ground and space (forming new type of TLE). Not every gamma-ray radiation can be measured from space because of attenuation, and TGFs are only a fraction of X- and gammarays production from clouds (Celestin et al., 2015). Such new TLEs could lead to better understanding of radiation from thunderstorms.

TARANIS is closely related to ASIM mission that is also focused on observing TGFs and TLEs produced by electrical activity of thunderstorms. ASIM was launched on April 2, 2018, and was placed in Columbus module of the ISS. The orbit of the ISS has an inclination of $51.6^{\circ}$ and drifts $6^{\circ}$ westward per day-in $\sim 2$ months, it covers all local times. Its altitude is the lowest low Earth orbit and varies from 370 to $460 \mathrm{~km}$. ASIM is equipped with 2 main tools: the Modular X- and Gamma-ray System (MXGS) and the Modular Multispectral Imaging Array (MMIA) (Neubert et al., 2019). Thanks to the fact that ASIM is placed on the ISS, it is able to use the station's device-LIS - but for the same fact, the EM surrounding of ASIM is very noisy as the ISS devices produce large amounts of EM radiation. 
ASIM's MXGS is aimed to detect TGFs; more details on how it works can be found in Østgaard et al. (2019). ASIM's MMIA is a pair of microcameras and 3 photometers aimed to visually detect TLEs and lightning activity in the thunderclouds; more details on its properties can be found in Chanrion et al. (2019).

ASIM mission orbits lower than TARANIS is intended too; thus it is closer to the thunderstorms and exhibits lower attenuation for light and particles. On the other hand, it lacks TARANIS' 600- to $900-\mathrm{nm}$ photometer, which is placed in surrounding that is electromagnetically noisy (ISS devices) and can only detect photons (that, however, can be radiated by energetic electrons or positrons). Thus combined measurements performed by ASIM and LIS onboard the ISS and free-orbiting TARANIS will be mutually complementary.

Acknowledgements. The author would like to thank his supervisor, Prof. Jan Błęcki, for the help in the preparation of this article. The reviewers' comments were very helpful too. The work has been supported by the National Science Centre grant No. 2017/27/B/ST10/02285.

\section{REFERENCES}

Abestrobi. (2008). Own work, CC BY-SA 3.0, https://commons.wikimedia.org/w/index.php?curid=4262250.

Aplin K.L., Harrison R.G., and Rycroft M.J. (2008). Investigating earth's atmospheric electricity: A role model for planetary studies. Space Science Reviews, 137(1-4), 11-27. https://doi.org/10.1007/s11214-008-9372-x

Barrington-Leigh C.P., Inan U.S., and Stanley M.A. (2001). Identification of sprites and elves with intensified video and broadband array photometry. Journal of Geophysical Research: Space Physics, 106(A2), 1741-1750. https://doi.org/10.1029/2000JA000073

Barrington-Leigh C.P., Inan U.S., Stanley M.A., and Cummer S.A. (1999). Sprites triggered by negative lightning discharges. Geophysical Research Letters, 26(24), 3605-3608. https://doi.org/10.1029/1999GL010692

Bell T.F., Pasko V.P., and Inan U.S. (1995). Runaway electrons as a source of red sprites in the mesosphere. Geophysical Research Letters, 22(16), 2127-2130. https://doi.org/10.1029/95GL02239

Bell T.F., Reising S.C., and Inan U.S. (1998). Intense continuing currents following positive cloud-to-ground lightning associated with red sprites. Geophysical Research Letters, 25(8), 1285-1288. https://doi.org/10.1029/98GL00734

Bethe H. (1930). Zur Theorie des Durchgangs schneller Korpuskularstrahlen durch Materie. Annalen Der Physik, 397(3), 325-400. https://doi.org/10.1002/andp.19303970303

Blanc E., Farges T., Brebion D., Labarthe A., and Melnikov V. (2006). Observations of Sprites From Space At the Nadir: The LSO (Lightning and Sprite Observations) Experiment on Board of the International Space Station. In M. Füllekrug (Ed.), Sprites, Elves and Intense Lightning Discharges (pp. 151-166). https://doi.org/10.1007/1-4020-4629-4_7

Blanc E., Farges T., Roche R., Brebion D., Hua T., Labarthe A., and Melnikov V. (2004). Nadir observations of sprites from the International Space Station. Journal of Geophysical Research: Space Physics, 109(A2), 1-8. https://doi.org/10.1029/2003JA009972 
Blanc E., Le Mer-Dachard F., Ravel K., Sato M., Farges T., Hébert P., ... Binet R. (2012). Taranis MCP: a joint instrument for accurate monitoring of transient luminous event in the upper atmosphere. In E. Armandillo, N. Karafolas, and B. Cugny (Eds.), International Conference on Space Optics-ICSO 2012 (Vol. 10564, p. 34). https://doi.org/10.1117/12.2309048

Blanc E., Lefeuvre F., Roussel-Dupré R., and Sauvaud J.-A. (2007). TARANIS: A microsatellite project dedicated to the study of impulsive transfers of energy between the Earth atmosphere, the ionosphere, and the magnetosphere. Advances in Space Research, 40(8), 1268-1275. https://doi.org/10.1016/j.asr.2007.06.037

Błęcki J., and Mizerski K. (2018). Subtle structure of streamers under conditions resembling those of Transient Luminous Events. Archives of Mechanics, 70(6), 1-16. https://doi.org/10.24423/aom.3009

Błęcki J., Parrot M., and Wronowski R. (2009). ELF and VLF signatures of sprites registered onboard the low altitude satellite DEMETER. Annales Geophysicae, 27(6), 2599-2605. https://doi.org/10.5194/angeo-27-2599-2009

Boccippio D.J., Goodman S.J., and Heckman S.J. (2002). Regional Differences in Tropical Lightning Distributions. Journal of Applied Meteorology, 39(12), 2231-2248. https://doi.org/10.1175/1520-0450(2001)040<2231:rditld $>2.0 . c 0 ; 2$

Boccippio D.J., Williams E.R., Heckman S.J., Lyons W.A., Baker I.T., and Boldi R. (1995). Sprites, ELF Transients, and Positive Ground Strokes. Science, 269(5227), 1088-1091. https://doi.org/10.1126/science.269.5227.1088

Briels T., van Veldhuizen E., and Ebert U. (2008). Positive streamers in air and nitrogen of varying density: Experiments on similarity laws. Journal of Physics D: Applied Physics, 41(23). https://doi.org/10.1088/0022-3727/41/23/234008

Bugaev S.P., Litvinov E.A., Mesyats G.A., and Proskurovskii D.I. (1975). Explosive emission of electrons. Uspekhi Fizicheskih Nauk, 115(1), 101. https://doi.org/10.3367/UFNr.0115.197501d.0101

Carlson B., Lehtinen N., and Inan U.S. (2008). Runaway relativistic electron avalanche seeding in the Earth's atmosphere. Journal of Geophysical Research: Space Physics, 113(10), 1-5. https://doi.org/10.1029/2008JA013210

Celestin S., Xu W., and Pasko V.P. (2015). Variability in fluence and spectrum of high-energy photon bursts produced by lightning leaders. Journal of Geophysical Research A: Space Physics, 120(12), 10712-10723. https://doi.org/10.1002/2015JA021410

Chanrion O., Neubert T., Lundgaard Rasmussen I., Stoltze C., Tcherniak D., Jessen N.C., ... Lorenzen M. (2019). The Modular Multispectral Imaging Array (MMIA) of the ASIM Payload on the International Space Station. Space Science Reviews, 215(4). https://doi.org/10.1007/s11214-019-0593-y

Chanrion O., Neubert T., Mogensen A., Yair Y., Stendel M., Singh R., and Siingh D. (2017). Profuse activity of blue electrical discharges at the tops of thunderstorms. Geophysical Research Letters, 44(1), 496-503. https://doi.org/10.1002/2016GL071311

Chen A.B., Kuo C.L., Lee Y.J., Su H. T., Hsu R. R., Chern J.L., ... Lee L.C. (2008). Global distributions and occurrence rates of transient luminous events. Journal of Geophysical Research: Space Physics, 113(8), 1-8. https://doi.org/10.1029/2008JA013101 
Chern J.-S., Wu A.-M., and Lin S.-F. (2014). Globalization extension of transient luminous events from FORMOSAT-2 observation. Acta Astronautica, 98(5), 64-70. https://doi.org/10.1016/j.actaastro.2014.01.014

Christian H.J., Blakeslee R.J., and Goodman S.J. (1989). The detection of lightning from geostationary orbit. Journal of Geophysical Research, 94(D11), 13329. https://doi.org/10.1029/JD094iD11p13329

Colman J.J., Roussel-Dupré R., and Triplett L. (2010). Temporally self-similar electron distribution functions in atmospheric breakdown: The thermal runaway regime. Journal of Geophysical Research: Space Physics, 115(A3), n/a-n/a. https://doi.org/10.1029/2009JA014509

Connaughton V., Briggs M.S., Xiong S., Dwyer J.R., Hutchins M.L., Grove J.E., ... WilsonHodge C. (2013). Radio signals from electron beams in terrestrial gamma ray flashes. Journal of Geophysical Research: Space Physics, 118(5), 2313-2320. https://doi.org/10.1029/2012JA018288

Cooray V. (2014). The Lightning Flash. In V. Cooray (Ed.), Lightning Protection for People and Property. https://doi.org/10.1007/978-1-4684-6548-8_4

Cummer S.A. (1997). Lightning and Ionospheric Remote Sensing Using Vlf / Elf Radio Atmospherics.

Cummer S.A. (2003). Current moment in sprite-producing lightning. Journal of Atmospheric and Solar-Terrestrial Physics, 65(5), 499-508. https://doi.org/10.1016/S13646826(02)00318-8

Cummer S.A., Frey H.U., Mende S.B., Hsu R.R., Su H.T., Chen A.B., ... Takahashi Y. (2006). Simultaneous radio and satellite optical measurements of high-altitude sprite current and lightning continuing current. Journal of Geophysical Research: Space Physics, 111(10), 16. https://doi.org/10.1029/2006JA011809

Cummer S.A., Inan U.S., Bell T.F., and Barrington-Leigh C.P. (1998). ELF radiation produced by electrical currents in sprites. Geophysical Research Letters, 25(8), 1281-1284. https://doi.org/10.1029/98GL50937

Cummer S.A., Jaugey N., Li J., Lyons W.A., Nelson T.E., and Gerken E.A. (2006). Submillisecond imaging of sprite development and structure. Geophysical Research Letters, 33(4), 30-33. https://doi.org/10.1029/2005GL024969

Cummer S.A., and Stanley M.A. (1999). Submillisecond resolution lightning currents and sprite development: Observations and implications. Geophysical Research Letters, 26(20), 32053208. https://doi.org/10.1029/1999GL003635

Drüe C., Hauf T., Finke U., Keyn S., and Kreyer O. (2007). Comparison of a SAFIR lightning detection network in northern Germany to the operational BLIDS network. Journal of Geophysical Research, 112(D18), D18114. https://doi.org/10.1029/2006JD007680

Dwyer J.R., and Babich L. (2012). Reply to comment by A.V. Gurevich et al. On "Low-energy electron production by relativistic runaway electron avalanches in air". Journal of Geophysical Research: Space Physics, 117(A4), n/a-n/a. https://doi.org/10.1029/2011JA017487

Dwyer J.R., Smith D.M., and Cummer S.A. (2012). High-energy atmospheric physics: Terrestrial gamma-ray flashes and related phenomena. Space Science Reviews, 173(1-4), 133-196. https://doi.org/10.1007/s11214-012-9894-0 
Dwyer J.R., and Uman M.A. (2014). The physics of lightning. Physics Reports, 534(4), 147241. https://doi.org/10.1016/j.physrep.2013.09.004

Ebert U., Montijn C., Briels T., Hundsdorfer W., Meulenbroek B., Rocco A., and Veldhuizen E.M. van. (2006). The multiscale nature of streamers. Plasma Sources Science and Technology, 15(2), S118-S129. https://doi.org/10.1088/0963-0252/15/2/S14

Ebert U., Nijdam S., Li C., Luque A., Briels T., and van Veldhuizen E. (2010). Review of recent results on streamer discharges and discussion of their relevance for sprites and lightning. Journal of Geophysical Research: Space Physics, 115(A7), 1-13. https://doi.org/10.1029/2009ja014867

Fishman G.J., Bhat P. N., Mallozzi R., Horack J. M., Koshut T., Kouveliotou C., ... Christian H.J. (1994). Discovery of intense gamma-ray flashes of atmospheric origin. Science, 264(5163), 1313-1316. https://doi.org/10.1126/science.264.5163.1313

Franz R.C., Nemzek R.J., and Winckler J.R. (1990). Television image of a large upward electrical discharge above a thunderstorm system. Science. https://doi.org/10.1126/science.249.4964.48

Friis-Christensen E., Lühr H., and Hulot G. (2006). Swarm: A constellation to study the Earth's magnetic field. Earth, Planets and Space, 58(4), 351-358. https://doi.org/10.1186/BF03351933

Füllekrug M., Hanuise C., and Parrot M. (2011). Experimental simulation of satellite observations of $100 \mathrm{kHz}$ radio waves from relativistic electron beams above thunderclouds. Atmospheric Chemistry and Physics, 11(2), 667-673. https://doi.org/10.5194/acp-11-6672011

Füllekrug M., Moudry D.R., Dawes G., and Sentman D.D. (2001). Mesospheric sprite current triangulation. Journal of Geophysical Research: Atmospheres, 106(D17), 20189-20194. https://doi.org/10.1029/2001JD900075

Füllekrug M., Parrot M., Ash M., Astin I., Williams P., and Talhi R. (2009). Transionospheric attenuation of $100 \mathrm{kHz}$ radio waves inferred from satellite and ground based observations. Geophysical Research Letters, 36(6), 1-5. https://doi.org/10.1029/2008GL036988

Füllekrug M., Roussel-Dupré R., Symbalisty E.M.D., Chanrion O., Odzimek A., van der Velde O.A., and Neubert T. (2010). Relativistic runaway breakdown in low-frequency radio. Journal of Geophysical Research: Space Physics, 115(1), 1-10. https://doi.org/10.1029/2009JA014468

Füllekrug M., Roussel-Dupré R., Symbalisty E.M.D., Colman J.J., Chanrion O., Soula S., ... Neubert T. (2011). Relativistic electron beams above thunderclouds. Atmospheric Chemistry and Physics, 11(15), 7747-7754. https://doi.org/10.5194/acp-11-7747-2011

Gerken E.A., and Inan U.S. (2002). A survey of streamer and diffuse glow dynamics observed in sprites using telescopic imagery. Journal of Geophysical Research: Space Physics, 107(A11), 1-12. https://doi.org/10.1029/2002JA009248

Gerken E.A., and Inan U.S. (2003). Observations of decameter-scale morphologies in sprites. Journal of Atmospheric and Solar-Terrestrial Physics, 65(5), 567-572. https://doi.org/10.1016/S1364-6826(02)00333-4

Gerken E.A., Inan U.S., and Barrington-Leigh C.P. (2000). Telescopic imaging of sprites. Geophysical Research Letters, 27(17), 2637-2640. https://doi.org/10.1029/2000GL000035 
Gurevich A.V., Milikh G.M., and Roussel-Dupré R. (1992). Runaway electron mechanism of air breakdown and preconditioning during a thunderstorm. Physics Letters A, 165(5-6), 463-468. https://doi.org/10.1016/0375-9601(92)90348-P

Gurevich A.V., and Zybin K.P. (2001). Runaway breakdown and electric discharges in $\begin{array}{lllll}\text { thunderstorms. Uspekhi Fizicheskih } & 1177 .\end{array}$ https://doi.org/10.3367/ufnr.0171.200111b.1177

Hess V. (1912). Über Beobachtungen der durchdringenden Strahlung bei sieben Freiballonfahrten. Physikalische Zeitschrift 13, 1084-1091.

Iudin D.I., Davydenko S.S., Gotlib V.M., Dolgonosov M.S., and Zelenyi L.M. (2018). Physics of lightning: New model approaches and prospects of the satellite observations. Uspekhi Fizicheskih Nauk, 188(08), 850-864. https://doi.org/10.3367/ufnr.2017.04.038221

Jacobson A.R., Holzworth R.H., and Shao X.M. (2011). Observations of multi-microsecond VHF pulsetrains in energetic intracloud lightning discharges. Annales Geophysicae, 29(9), 1587-1604. https://doi.org/10.5194/angeo-29-1587-2011

Jacobson A.R., and Light T.E.L. (2003). Bimodal radio frequency pulse distribution of intracloud-lightning signals recorded by the FORTE satellite. Journal of Geophysical Research: Atmospheres, 108(D9), n/a-n/a. https://doi.org/10.1029/2002jd002613

Jehl A., Farges T., and Blanc E. (2013). Color pictures of sprites from non-dedicated observation on board the International Space Station. Journal of Geophysical Research: Space Physics, 118(1), 454-461. https://doi.org/10.1029/2012JA018144

Johnson M.P., and Inan U.S. (2000). Sferic clusters associated with early/Fast VLF events. Geophysical Research Letters, 27(9), 1391-1394. https://doi.org/10.1029/1999GL010757

Kammae T., Stenbaek-Nielsen H.C., McHarg M.G., and Haaland R.K. (2012). Diameter-speed relation of sprite streamers. Journal of Physics D: Applied Physics, 45(27). https://doi.org/10.1088/0022-3727/45/27/275203

Kochkin P., Lehtinen N., Van Deursen A.P.J., and Østgaard N. (2016). Pilot system development in metre-scale laboratory discharge. Journal of Physics D: Applied Physics, 49(42). https://doi.org/10.1088/0022-3727/49/42/425203

Kosar B.C., Liu N., and Rassoul H.K. (2012). Luminosity and propagation characteristics of sprite streamers initiated from small ionospheric disturbances at subbreakdown conditions. Journal of Geophysical Research: Space Physics, 117(8), 1-9. https://doi.org/10.1029/2012JA017632

Kosar B.C., Liu N., and Rassoul H.K. (2013). Formation of sprite streamers at subbreakdown conditions from ionospheric inhomogeneities resembling observed sprite halo structures. Geophysical Research Letters, 40(23), 6282-6287. https://doi.org/10.1002/2013GL058294

Kudintseva I.G., Nickolaenko A.P., and Hayakawa M. (2010). Transient Electric Field in the Mesosphere above a $\Gamma$-shape Lightning Stroke. Surveys in Geophysics, 31(4), 427-448. https://doi.org/10.1007/s10712-010-9095-x

Kulak A., Kubisz J., Klucjasz S., Michalec A., Mlynarczyk J., Nieckarz Z., ... Zieba S. (2014). Extremely low frequency electromagnetic field measurements at the Hylaty station and methodology of signal analysis. Radio Science, 49(6), 361-370. https://doi.org/10.1002/2014RS005400 
Lang T.J., Rutledge S.A., and Wiens K.C. (2004). Origins of positive cloud-to-ground lightning flashes in the stratiform region of a mesoscale convective system. Geophysical Research Letters, 31(10). https://doi.org/10.1029/2004GL019823

Lefeuvre F., Blanc E., Pinçon J.-L., Roussel-Dupré R., Lawrence D., Sauvaud J.-A., ... Lagoutte D. (2008). TARANIS-A Satellite Project Dedicated to the Physics of TLEs and TGFs. Space Science Reviews, 137(1-4), 301-315. https://doi.org/10.1007/s11214-0089414-4

Lefeuvre F., Marshall R.A., Pinçon J.-L., Inan U.S., Lagoutte D., Parrot M., and Berthelier J.J. (2009). On remote sensing of transient luminous events parent lightning discharges by ELF/VLF wave measurements on board a satellite. Journal of Geophysical Research: Space Physics, 114(9), 1-13. https://doi.org/10.1029/2009JA014154

Lehtinen N., Walt M., Inan U.S., Bell T.F., and Pasko V.P. (1996). $\gamma$-Ray emission produced by a relativistic beam of runaway electrons accelerated by quasi-electrostatic thundercloud fields. Geophysical Research Letters, 23(19), 2645-2648. https://doi.org/10.1029/96GL02573

Li J., Cummer S.A., Lyons W.A., and Nelson T.E. (2008). Coordinated analysis of delayed sprites with high-speed images and remote electromagnetic fields. Journal of Geophysical Research Atmospheres, 113(20), 1-11. https://doi.org/10.1029/2008JD010008

Liu N., Dwyer J.R., and Cummer S.A. (2017). Elves Accompanying Terrestrial Gamma Ray Flashes. Journal of Geophysical Research: Space Physics, 122(10), 10,563-10,576. https://doi.org/10.1002/2017JA024344

Liu N., Dwyer J.R., Stenbaek-Nielsen H.C., and McHarg M.G. (2015). Sprite streamer initiation from natural mesospheric structures. Nature Communications, 6(May), 1-9. https://doi.org/10.1038/ncomms8540

Liu N., Kosar B.C., Sadighi S., Dwyer J.R., and Rassoul H.K. (2012). Formation of streamer discharges from an isolated ionization column at subbreakdown conditions. Physical Review Letters, 109(2). https://doi.org/10.1103/PhysRevLett.109.025002

Liu N., and Pasko V.P. (2004). Effects of photoionization on propagation and branching of positive and negative streamers in sprites. Journal of Geophysical Research: Space Physics, 109(A4), 1-18. https://doi.org/10.1029/2003JA010064

Lu G., Cummer S.A., Li J., Zigoneanu L., Lyons W.A., Stanley M.A., ... Samaras T. (2013). Coordinated observations of sprites and in-cloud lightning flash structure. Journal of Geophysical Research Atmospheres, 118(12), 6607-6632. https://doi.org/10.1002/jgrd.50459

Luque A., and Ebert U. (2009). Emergence of sprite streamers from screening-ionization waves in the lower ionosphere. Nature Geoscience, 2(11), 757-760. https://doi.org/10.1038/ngeo662

Luque A., and Gordillo-Vázquez F.J. (2011). Sprite beads originating from inhomogeneities in the mesospheric electron density. Geophysical Research Letters, 38(4), 1-5. https://doi.org/10.1029/2010GL046403

Lyu F., Cummer S.A., Krehbiel P.R., Rison W., Briggs M.S., Cramer E., ... Stanbro M. (2018). Very High Frequency Radio Emissions Associated With the Production of Terrestrial Gamma-Ray Flashes. Geophysical Research Letters, 45(4), 2097-2105. https://doi.org/10.1002/2018GL077102 
Marisaldi M., Fuschino F., Labanti C., Galli M., Longo F., Del Monte E., ... Salotti L. (2010). Detection of terrestrial gamma ray flashes up to $40 \mathrm{MeV}$ by the AGILE satellite. Journal of Geophysical Research: Space Physics, 115(A3), n/a-n/a. https://doi.org/10.1029/2009JA014502

Marisaldi M., Fuschino F., Tavani M., Dietrich S., Price C., Galli M., ... Verrecchia F. (2014). Properties of terrestrial gamma ray flashes detected by AGILE MCAL below $30 \mathrm{MeV}$. Journal of Geophysical Research: Space Physics, 119, 1337-1355. https://doi.org/10.1002/2013JA019301

Marshall R.A., and Inan U.S. (2005). High-speed telescopic imaging of sprites. Geophysical Research Letters, 32(5), 1-4. https://doi.org/10.1029/2004GL021988

Marshall T.C., and Stolzenburg M. (2001). Voltages inside and just above thunderstorms. Journal of Geophysical Research: Atmospheres, 106(D5), 4757-4768. https://doi.org/10.1029/2000JD900640

Mende S.B., Chang Y.S., Chen A.B., Frey H.U., Fukunishi H., Geller S.P., ... Takahashi Y. (2006). SPACECRAFT BASED STUDIES OF TRANSIENT LUMINOUS EVENTS. In M. Fullekrug (Ed.), Sprites, Elves and Intense Lightning Discharges (pp. 123-149). https://doi.org/10.1007/1-4020-4629-4_6

Mlynarczyk J., Bór J., Kulak A., Popek M., and Kubisz J. (2015). An unusual sequence of sprites followed by a secondary TLE: An analysis of ELF radio measurements and optical observations. Journal of Geophysical Research: Space Physics, 120(3), 2241-2254. https://doi.org/10.1002/2014JA020780

Moss G.D., Pasko V.P., Liu N., and Veronis G. (2006). Monte Carlo model for analysis of thermal runaway electrons in streamer tips in transient luminous events and streamer zones of lightning leaders. Journal of Geophysical Research: Space Physics, 111(2), 1-37. https://doi.org/10.1029/2005JA011350

Nag A., and Rakov V.A. (2012). Positive lightning: An overview, new observations, and inferences. 117(January), 1-20. https://doi.org/10.1029/2012JD017545

Nagano M., and Watson A.A. (2000). Observations and implications of the ultrahigh-energy cosmic rays. Reviews of Modern Physics, 72(3), 689-732. https://doi.org/10.1103/RevModPhys.72.689

Neubert T., Allin T.H., Stenbaek-Nielsen H., and Blanc E. (2001). Sprites Over Europe. Geophysical Research Letters, 28(18), 3585-3588. https://doi.org/10.1029/2001GL013427

Neubert T., Østgaard N., Reglero V., Blanc E., Chanrion O., Oxborrow C.A., ... Bhanderi D. D.V. (2019). The ASIM Mission on the International Space Station. Space Science Reviews, 215(2). https://doi.org/10.1007/s11214-019-0592-z

Neubert T., Rycroft M. J., Farges T., Blanc E., Chanrion O., Arnone E., ... Crosby N. (2008). Recent results from studies of electric discharges in the mesosphere. In Surveys in Geophysics (Vol. 29). https://doi.org/10.1007/s10712-008-9043-1

Ohkubo A., Fukunishi H., Takahashi Y., and Adachi T. (2005). VLF/ELF sferic evidence for incloud discharge activity producing sprites. Geophysical Research Letters, 32(4), 1-4. https://doi.org/10.1029/2004GL021943

Oreshkin E.V., Barengolts S.A., Chaikovsky S.A., and Oreshkin V.I. (2012). Simulation of the runaway electron beam formed in a discharge in air at atmospheric pressure. Physics of Plasmas, 19(4), 043105. https://doi.org/10.1063/1.3695349 
Østgaard N., Balling J.E., Bjørnsen T., Brauer P., Budtz-Jørgensen C., Bujwan W., ... Yang S. (2019). The Modular X- and Gamma-Ray Sensor (MXGS) of the ASIM Payload on the International Space Station. Space Science Reviews, Vol. 215. https://doi.org/10.1007/s11214-018-0573-7

Paiva G.S., Pavao A.C., and Bastos C.C. (2009). 'Seed' electrons from muon decay for runaway mechanism in the terrestrial gamma ray flash production. Journal of Geophysical Research Atmospheres, 114(3). https://doi.org/10.1029/2008JD010468

Parrot M., Berthelier J.J., Lebreton J.P., Treumann R.A., and Rauch J.-L. (2008). DEMETER observations of EM emissions related to thunderstorms. Space Science Reviews, 137(1-4), 511-519. https://doi.org/10.1007/s11214-008-9347-y

Parrot M., Sauvaud J.-A., Soula S., Pinçon J.-L., and van der Velde O.A. (2013). Ionospheric density perturbations recorded by DEMETER above intense thunderstorms. Journal of Geophysical Research: Space Physics, 118(8), 5169-5176. https://doi.org/10.1002/jgra.50460

Pasko V. P. (2006). Theoretical Modeling of Sprites and Jets. In M. et al Füllekrug (Ed.), Sprites, Elves and Intense Lightning Discharges (pp. 253-311). https://doi.org/10.1007/1-40204629-4_12

Pasko V.P. (2007). Red sprite discharges in the atmosphere at high altitude: The molecular physics and the similarity with laboratory discharges. Plasma Sources Science and Technology, 16(1), 13-29. https://doi.org/10.1088/0963-0252/16/1/S02

Pasko V.P., Inan U.S., Bell T.F., and Reising S.C. (1998). Mechanism of ELF radiation from sprites. Geophysical Research Letters, 25(18), 3493-3496. https://doi.org/10.1029/98GL02631

Pasko V.P., Inan U.S., Bell T.F., and Taranenko Y. (1997). Sprites produced by quasielectrostatic heating and ionization in the lower ionosphere. Journal of Geophysical Research A: Space Physics, 102(A3), 4529-4561. https://doi.org/10.1029/96JA03528

Pasko V.P., Yair Y., and Kuo C.L. (2012). Lightning related transient luminous events at high altitude in the earth's atmosphere: Phenomenology, mechanisms and effects. In Space Science Reviews (Vol. 168). https://doi.org/10.1007/s11214-011-9813-9

Qin J., Celestin S., and Pasko V.P. (2012). Low frequency electromagnetic radiation from sprite streamers. Geophysical Research Letters, 39(22), 1-5. https://doi.org/10.1029/2012GL053991

Raizer Y.P. (1991). Gas Discharge Physics (J. E. Allen, Ed.). https://doi.org/10.1007/978-3642-61247-3

Rakov V.A. (2013). The Physics of Lightning. (April), 701-729. https://doi.org/10.1007/s10712-013-9230-6

Rakov V.A., and Uman M.A. (2003). Lightning: Physics and Effects. Cambridge, United Kingdom: Cambridge University Press.

Roberts O.J., Fitzpatrick G., Stanbro M., McBreen S., Briggs M.S., Holzworth R.H., ... Mailyan B.G. (2018). The First Fermi-GBM Terrestrial Gamma Ray Flash Catalog. Journal of Geophysical Research: Space Physics, 123(5), 4381-4401. https://doi.org/10.1029/2017JA024837 
Roussel-Dupré R., Symbalisty E.M.D., Taranenko Y., and Yukhimuk V. (1998). Simulations of high-altitude discharges initiated by runaway breakdown. Journal of Atmospheric and Solar-Terrestrial Physics, 60(7-9), 917-940. https://doi.org/10.1016/S13646826(98)00028-5

Rutheford E. (1911). The Scattering of $\alpha$ and $\beta$ Particles by Matter and the Structure of the Atom. Philosophical Magazine, 21(6), 669-688.

Rycroft M.J., and Odzimek A. (2010). Effects of lightning and sprites on the ionospheric potential, and threshold effects on sprite initiation, obtained using an analog model of the global atmospheric electric circuit. Journal of Geophysical Research: Space Physics, 115(A6), n/a-n/a. https://doi.org/10.1029/2009JA014758

São Sabbas F.T., Sentman D.D., Wescott E.M., Pinto O., Mendes O., and Taylor M.J. (2003). Statistical analysis of space-time relationships between sprites and lightning. Journal of Atmospheric and Solar-Terrestrial Physics, 65(5), 525-535. https://doi.org/10.1016/S13646826(02)00326-7

Sarria D., Lebrun F., Blelly P.L., Chipaux R., Laurent P., Sauvaud J.-A., ... Lindsey-Clark M. (2017). TARANIS XGRE and IDEE detection capability of terrestrial gamma-ray flashes and associated electron beams. Geoscientific Instrumentation, Methods and Data Systems, 6(2), 239-256. https://doi.org/10.5194/gi-6-239-2017

Sato M., Ushio T., Morimoto T., Kikuchi M., Kikuchi H., Adachi T., ... Kawasaki Z.I. (2015). Overview and early results of the global lightning and sprite measurements mission. Journal of Geophysical Research, 120(9), 3822-3851. https://doi.org/10.1002/2014JD022428

Sentman D.D., Wescott E.M., Osborne D.L., Hampton D.L., and Heavner M.J. (1995). Preliminary results from the Sprites94 Aircraft Campaign: 1. Red sprites. Geophysical Research Letters, 22(10), 1205-1208. https://doi.org/10.1029/95GL00583

Stanley M.A., Brook M., Krehbiel P.R., and Cummer S.A. (2000). Detection of daytime sprites via a unique sprite ELF signature. Geophysical Research Letters, 27(6), 871-874. https://doi.org/10.1029/1999GL010769

Stenbaek-Nielsen H.C., Kammae T., McHarg M.G., and Haaland R.K. (2013). High-Speed Observations of Sprite Streamers. Surveys in Geophysics, 34(6), 769-795. https://doi.org/10.1007/s10712-013-9224-4

Stenbaek-Nielsen H.C., and McHarg M.G. (2008). High time-resolution sprite imaging: Observations and implications. Journal of Physics D: Applied Physics, 41(23). https://doi.org/10.1088/0022-3727/41/23/234009

Stolzenburg M., and Marshall T.C. (2008). Charge Structure and Dynamics in Thunderstorms. (November 2007), 355-372. https://doi.org/10.1007/s11214-008-9338-z

Stolzenburg M., Rust W.D., and Marshall T.C. (1998). Electrical structure in thunderstorm convective regions: 3. Synthesis. Journal of Geophysical Research: Atmospheres, 103(D12), 14097-14108. https://doi.org/10.1029/97JD03545

Surkov V.V., and Hayakawa M. (2012). Underlying mechanisms of transient luminous events: A review. Annales Geophysicae, 30(8), 1185-1212. https://doi.org/10.5194/angeo-30-11852012

Taranenko Y., and Roussel-Dupré R. (1996). High altitude discharges and gamma-ray flashes: A manifestation of runaway air breakdown. Geophysical Research Letters, 23(5), 571-574. https://doi.org/10.1029/95GL03502 
Taylor W.L., and Sao K. (1970). ELF Attenuation Rates and Phase Velocities Observed From Slow-Tail Components of Atmospherics. Radio Science, 5(12), 1453-1460. https://doi.org/10.1029/RS005i012p01453

van der Velde O.A., Mika Á., Soula S., Haldoupis C., Neubert T., and Inan U.S. (2006). Observations of the relationship between sprite morphology and in-cloud lightning processes. Journal of Geophysical Research Atmospheres, 111(15), 1-8. https://doi.org/10.1029/2005JD006879

Wescott E.M., Sentman D.D., Osborne D.L., Hampton D.L., and Heavner M.J. (1995). Preliminary results from the Sprites94 Aircraft Campaign: 2. Blue jets. Geophysical Research Letters, 22(10), 1209-1212. https://doi.org/10.1029/95GL00582

Wescott E.M., Stenbaek-Nielsen H.C., Sentman D.D., Heavner M.J., Moudry D.R., and Sabbas F. T. S. (2001). Triangulation of sprites, associated halos and their possible relation to causative lightning and micrometeors. Journal of Geophysical Research: Space Physics, 106(A6), 10467-10477. https://doi.org/10.1029/2000ja000182

Wilson C.T.R. (1924). Electric Field of a Thundercloud and Some of Its Effects. Proceedings of the Physical Society of London, 37(1), 32D-37D. https://doi.org/10.1088/1478$7814 / 37 / 1 / 314$

Wilson C.T.R. (1925). The Acceleration of beat-particles in Strong Electric Fields such as those of Thunderclouds. Mathematical Proceedings of the Cambridge Philosophical Society, 22(4), 534-538. https://doi.org/10.1017/S0305004100003236

Winckler J.R., Lyons W.A., Nelson T.E., and Nemzek R.J. (1996). New high-resolution groundbased studies of sprites. Journal of Geophysical Research: Atmospheres, 101(D3), 69977004. https://doi.org/10.1029/95JD03443

$\mathrm{Xu}$ W., Celestin S., Pasko V.P., and Marshall R.A. (2017). A novel type of transient luminous event produced by terrestrial gamma-ray flashes. Geophysical Research Letters, 44(5), 2571-2578. https://doi.org/10.1002/2016GL072400

Yair Y. (2004). New observations of sprites from the space shuttle. Journal of Geophysical Research, 109(D15), D15201. https://doi.org/10.1029/2003JD004497

Yukhimuk V., Roussel-Dupré R., Symbalisty E.M.D., and Taranenko Y. (1998). Optical characteristics of red sprites produced by runaway air breakdown. Journal of Geophysical Research: Atmospheres, 103(D10), 11473-11482. https://doi.org/10.1029/98JD00348

Zabotin N.A., and Wright J.W. (2001). Role of meteoric dust in sprite formation. Geophysical Research Letters, 28(13), 2593-2596. https://doi.org/10.1029/2000GL012699

Zelenyi L.M., Gurevich A.V., Klimov S.I., Angarov V.N., Batanov O.V., Bogomolov A.V., ... Yashin I.V. (2014). The academic Chibis-M microsatellite. Cosmic Research, 52(2), 87-98. https://doi.org/10.1134/s0010952514010110

Received: 2019-10-03,

Reviewed: 2019-12-05, by K. Mizerski, and 2019-11-15,

Accepted: 2019-12-10. 